\title{
Comparison of CNG and LNG Technologies for Transportation Applications
}

\section{Final Subcontract Report June 1991 - Decem er 1991}

NREL/TP--230-4638

DE92 001204

J.E. Sinor

J.E. Sinor Consultants

Niwot, $C O$

NREL technical monitor: B. Bailey

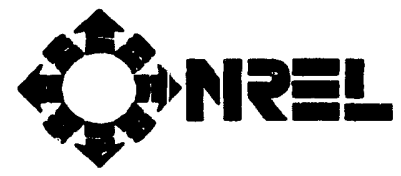

National Renewable Energy Laboratory

(formerly the Solar Energy Research Institute) 1617 Cole Boulevard Golden, Colorado 80401-3393

A Division of Midwest Research Institute Operated for the U.S. Department of Energy under Contract No. DE-AC02-83CH10093

Prepared under Subcontract No. CJ-1-11145-1

January 1992 
On September 16, 1991, the Solar Energy Research Institute was designated a national laboratory, and its name was changed to the National Renewable Energy Laboratory.

This publication was reproduced from the best available camera-ready copy submitted by the subcontractor and received minimal review at NREL.

\section{NOTICE}

This report was prepared as an account of work sponsored by an agency of the United States govemment. Neither the United States government nor a agency thereof, nor any of their employees, makes any warranty, express or implied, or assumes any legal liability or responsibility for the accuracy, cc: pleteness, or usefulness of any information, apparatus, product, or process disclosed, or represents that its use would not infringe privately owned righ Reference herein to any specific commercial prodisct, process, or service by trade name, trademark, manutacturer, or otherwise does not necessarily $c c$

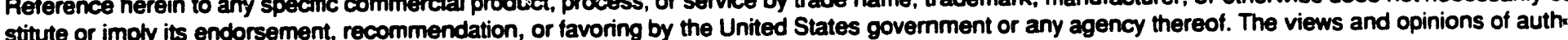
expressed herein do not necessarily state or reflect those of the United States government or any agency thereof.

Printed in the United States of America

Available from:

National Technical Information Service

U.S. Department of Commerce

5285 Port Royal Road

Springtield, VA 22161

Price: Microfiche A01

Printed Copy A04

Codes are used for pricing all publications. The code is determined by the number of pages in the publication. Information pertaining to the pricing cek can be fourui in the current issue of the following publications which are generally available in most libraries: Energy Research Abstracts (ERA); Gon ment Reports Announcements and Index (GRA and I); Scientific and Technical Abstract Reports (STAR); and publication NTIS-PR-360 available from N: at the above address. 


\section{CONTENTS}

INTRODUCTION

BACKGROUND $\quad 2$

COMPARISON OF FLUID PROPERTIES

COMPARISON OF FUEL PRODUCTION PROCESSES

Energy Used for CNG Compression $\quad 4$

Energy Used for LNG Liquefaction

Energy Used for Transportation $\quad 7$

$\begin{array}{ll}\text { Vehicle Refueling Time } & 12\end{array}$

COMPARISON OF END-USE CHARACTERISTICS

Potential Advantages of Liquid Fuel $\quad 14$

Potential Advantages of Cold Fuel 14

$\begin{array}{ll}\text { RELATIVE EFFECTS OF TANK WEIGHT } & 20\end{array}$

$\begin{array}{ll}\text { Tank Weight versus Volume } & 20\end{array}$

Tank Volume Needed for Heavy-Duty Trucks $\quad 20$

CNG versus LNG Comparisons $\quad 23$

Heavy-Duty Vehicles other than Trucks

VARIATIONS WITH LOCATION .

Effect of Temperature $\quad 33$

Effect of Miles Traveled $\quad 36$

Distance from Liquefaction Plant $\quad 36$

COMPARISON OF INFRASTRUCTURE COSTS $\quad 38$

COMPARISON OF GREENHOUSE EMISSIONS

Methane Emissions $\quad 39$

Effect of Engine Efficiency

Effect of Fuel Transportation $\quad 39$

Effect of Compression or Liquefaction $\quad 40$

Effect of Tank Weight on Mileage $\quad 40$

Effect of Tank Weight on Payload Loss $\quad 40$

Effect of Manufacturing Energy $\quad 41$

Composite Effects $\quad 41$

SAFETY CONSIDERATIONS $\quad 48$

CONCLUSIONS 49

$\begin{array}{lc}\text { REFERENCES } & 51\end{array}$ 


\section{FIGURES}

Figure 1. Typical CNG Vehicle Refueling Station with Fast-Fill and

Slow-Fill Systems
Figure $\quad 2 . \quad$ Effect of Initial Temperature and Pressure on Ideal Work of

Figure

Methane Compression or Liquefaction
3. Progress in Natural Gas Liquefaction Energy Efficiency

Figure

Figure

Figure

Figure

Figure

Figure

4. Estimated Efficiency of LNG Liquefiers

5. Energy Required for Liquefaction in State-of-the-Art Facilities 10

6. LNG Distribution System

7. Locations of Bulk LNG Facilities

8. Heavy-Duty $\mathrm{NO}_{\mathrm{x}}$ Emissions versus Peak Combustion Temperature

9. Compression Temperature for Different Compression Ratios and

Intake Temperatures

Figure

10. LNG Aircraft Auxiliary Power System

Figure

11. Fuel Tank Weight/Volume Curves

Figure

12. Truck Size/Mileage Relationship

Figure

13. Curb Weight versus Gross Vehicle Weight Rating 24

Figure

14. Truck Weight/Mileage Relationship

Figure

15. Truck Weight/Mileage Relationship

Figure

16. Potential Loss in Payload

Figure

17. Potential Loss in Payload

Figure

18. Effect of Tank Weight on Fuel Efficiency 29

Figure

19. Effect of Tank Weight on Fuel Efficiency

Figure

20. Locations of Case Studies

Figure

21. Effect of Ambient Temperature on Energy Efficiency

Figure

22. Effect of Population Density on Relative System Efficiency

Figure

23. Additional Energy Required to Manufacture Tanks when CNG is Used Instead of LNG

Figure

24. Differential Greenhouse Emissions for 100-Mile Range, 9,800-lb GVW Vehicle

Figure 25. Differential Greenhouse Emissions for 100-Mile Range,

Figure 26. Differential Greenhouse Emissions for 500-Mile Range,

Figure 27. Differential Greenhouse Emissions for 500-Mile Range, 33,000-lb GVW Vehicle

Figure 28. Differential Greenhouse Emissions for 500-Mile Range, 33,000-lb GVW Vehicle 


\section{INTRODUCTION}

The National Renewable Energy Laboratory (NREL), on behalf of the Department of Energy (DOE), has had a long-standing interest in advancing the use of alternative fuels for conserving energy and reducing the nation's dependence on foreign oil supplies. Successful application and use of alternative fuels requires that associated environmental issues be addressed. NREL requested that J.E. Sinor Consultants Inc. carry out a brief comparison of competing technologies for supply, storage, and delivery of natural gas to the transportation sector via the liquefied and compressed natural gas routes. Emphasis was to be placed on heavy-duty vehicles rather than automobiles and other light-duty vehicles.

This report therefore provides a head-to-head comparison of compressed natural gas (CNG) and liquefied natural gas (LNG) supplied to heavy-duty vehicles. The comparison includes an assessment of the overall efficiency of the fuel delivery system, the cost of the fuel supply system, the efficiency of use in heavy-duty vehicles, and the environmental impact of each technology. In accordance with DOE's fuel-neutral approach to alternative fuels, the study is not intended to promote one fuel or the other, but to present an unbiased comparison. 


\section{BACKGROUND}

Natural gas is a widely chosen alternative fuel for demonstration projects being carried out under the Alternative Motor Fuels Act (AMFA). Although there appear to be some obvious advantages to the use of LNG, particularly in transit buses and heavy-duty trucks, almost all the natural gas projects proposed to date involve the use of CNG. Because the average person is far less familiar with LNG, this may be just a matter of a normal time lag in technology transfer. A second possibility is that there are still some gaps in available technology for LNG. The third possibility is that there are inherent cost or other disadvantages to LNG that will always relegate it to a minor role.

If the third possibility is true, no action need be taken. But if either of the first two possibilities hold, it is possible that the country would be better off with some overall guidance from DOE. Carrying out research to fill technology gaps and providing the resources needed to accelerate technology transfer are two obvious functions of the DOE. Building the infrastructure, in terms of vehicles and refueling stations, needed to create a significant market for CNG will be extremely costly. If we find out somewhere down the road that LNG would have been better, we will have made an expensive detour.

Although there are numerous studies in the literature comparing the merits of various alternative fuels, LNG is always treated as a sidebar when discussing CNG versus other fuels. Thus the particular characteristics that distinguish LNG from CNG are not usually analyzed in any detail. This study was designed to highlight those differences.

Considering that this was a limited effort to explore whether an important policy issue exists, the analysis was limited to heavy-duty vehicles. This is the application where LNG would be most likely to have demonstrable advantages and would also be most easily implemented.

Analyses were carried out comparing LNG to CNG with respect to three issues of national interest:

- Relative energy efficiency

- Relative cost

- Relative greenhouse gas emissions. 


\section{COMPARISON OF FLUID PROPERTIES}

In this study, it is assumed that the chemical compositions of LNG and CNG are identical. In practice, that may or may not be the case. If the LNG comes from an import terrninal or a large liquefaction facility, any higher-boiling hydrocarbons will likely have been separated out for sale as individual products. For this reason, it is often assumed that LNG will be a more pure product with a more constant composition than CNG. However, if a small-scale liquefaction plant is used, or the LNG is obtained from a peak-shaving facility that liquefies the entire stream, the composition will be the same as the pipeline supply. Also, the output of large LNG plants is not necessarily controlled to a given methane percentage. Therefore, it seems premature and unjustified to make a general assumption that LNG will have compositional properties superior to CNG, although the potential clearly exists.

For comparison purposes, this study assumes that both LNG and CNG would be obtained from the same pipeline system and that no purification would take place during the process of liquefaction.

Given identical compositions, those characteristics that differ between LNG and CNG and that affect their use in some way are shown below (values are given for methane; natural gas, which is usually only $95 \%$ methane, will differ slightly):

$\begin{array}{lll} & \text { CNG } & \text { LNG } \\ \text { Physical state } & \text { Gas } & \text { Liquid } \\ \text { Temperature in vehicle tank } & \text { Ambient } & -162^{\circ} \mathrm{C} \\ \text { Temperature in vehicle tank } & \text { Ambient } & -259^{\circ} \mathrm{F} \\ \text { Typical pressure in tank } & 2,500-3,600 \mathrm{psig} & 10-50 \mathrm{psig} \\ \text { Typical pressure in tank } & 17.3-24.9 \mathrm{MPa} & 170-446 \mathrm{kPa} \\ \text { Typical density in tank } & 1.1-1.6 \mathrm{lb} / \mathrm{gal} & 3.5 \mathrm{lb} / \mathrm{gal} \\ \text { Typical specific gravity } & 0.13-0.19 & 0.42 \\ \text { Typical energy density (LHV) } & 23,000-34,000 \mathrm{Btu} / \mathrm{gal} & 75,000 \mathrm{Btu} / \mathrm{gal} \\ \text { Typical energy density (LHV) } & 6,500-9,500 \mathrm{MJ} / \mathrm{L} & 21,000 \mathrm{MJ} / \mathrm{L} \\ \text { Heat of vaporization } & & 220 \mathrm{Btu} / \mathrm{lb} \\ & & \end{array}$

In order to maintain it in a liquid state, LNG must be kept cold by storing and transporting it in double-walled, vacuum-insulated containers. All containers let some heat leak in, causing LNG to boil off and pressure to build up in the vapor space. Unless either vapor or liquid is withdrawn at a rate sufficient to counteract the boiloff rate, tank pressure will increase until the pressure setting of the relief valve is exceeded and some gas is vented to the atmosphere. This process will continue until eventually the entire liquid contents of the tank have been vaporized. By contrast, natural gas can be stored as CNG indefinitely without loss. This distinction is one reason why LNG may not be a good candidate for low-annual-mileage vehicles used by the general public. LNG tank manufacturers now claim that LNG can be stored for two weeks or more without venting, so that there is no boiloff problem for fleet vehicles used at least once a week. 


\section{COMPARISON OF FUEL PRODUCTION PROCESSES}

\section{ENERGY USED FOR CNG COMPRESSION}

To achieve reasonable values of tank weight and volume, CNG for vehicular use is usually compressed to pressures in the range of 2,500 to 3,600 psig. Because no pipelines operate in this pressure range, the natural gas must in all cases be compressed. The technology of gas compression and use at high pressures involves certain secondary aspects such as moisture removal and control of hydrate formation, but only the overall cost and energy used will be considered here.

The ideal work of isothermal compression can be obtained from a table of thermodynamic properties for methane using the relation

$$
\mathbf{W}=\mathrm{dH}-\mathbf{T d S}
$$

where W, H, T, and S are the ideal work, enthalpy, temperature, and entropy, respectively. Alternatively, it can be calculated from an equation of state, or approximated from the ideal gas law. Using the latter formula it can be seen that the energy required for compression is exponentially proportional to the ratio of the initial and final pressures. Thus it becomes sensitive to the pipeline supply pressure.

The energy required also depends upon the method used for vehicle refueling. As illustrated in Figure 1, there are two procedures in general use. In "slow-fill," a compressor is connected to all vehicles at once, and, over a period of several hours, the pressure is increased to the final fill pressure. This system requires the least energy for compression.

In the "fast-fill" technique, the compressor first fills an intermediate storage vessel or vessels, at least one of which is at an appreciably higher pressure than the desired vehicle fill pressure. If a 3,000 psi vehicle pressure is used, the storage pressure may have to be 4,000 psi. A single vehicle can then be filled in just a few minutes by connecting it to the storage vessel. Because the gas must be compressed to a higher pressure in the intermediate storage vessel than the final vehicle fill pressure, a fast-fill system uses more energy than a slow-fill system. The excess energy can be minimized by using a series of vessels at successively higher pressures, called a cascade, and filling the vehicle from each in turn.

The minimum theoretical work of compression to $2,500 \mathrm{psig}$, as a function of initial temperature and pressure, is shown in Figure 2. For actual energy required, one might consider the efficiency of a large compressor to be on the order of 75\%. Thus, based on Figure 2, we may conclude that the typical energy requirement for compression is on the order of $400 \mathrm{Btu} / \mathrm{lb}$, or about $2 \%$ of the energy value of the natural gas being compressed. Smaller compressors are less efficient. Specifications for the FuelMaker home refueling appliance for a single vehicle indicate an energy usage of about 700 to $1,000 \mathrm{Btu} / \mathrm{lb}(26)$. This would be a maximum of slightly less than $5 \%$ of the energy value of the natural gas. Thus a range of $2 \%$ to $5 \%$ encompasses all the reasonably expected values for energy used to compress CNG.

\section{ENERGY USED FOR LNG LIQUEFACTION}

\section{Theoretical Minimum Work}

Estimates of the energy required for liquefaction of natural gas vary over a much wider range than estimates for compression alone. This is because the energy required depends heavily on the liquefaction process chosen. If one simply goes to a thermodynamic chart and draws a line for isothermal compression followed by isentropic expansion to the saturated liquid curve, the ideal energy required for liquefaction would be as shown in Figure 2. If we consider that a liquefaction plant is most likely going to be located near a high-pressure natural gas pipeline, a typical inlet 


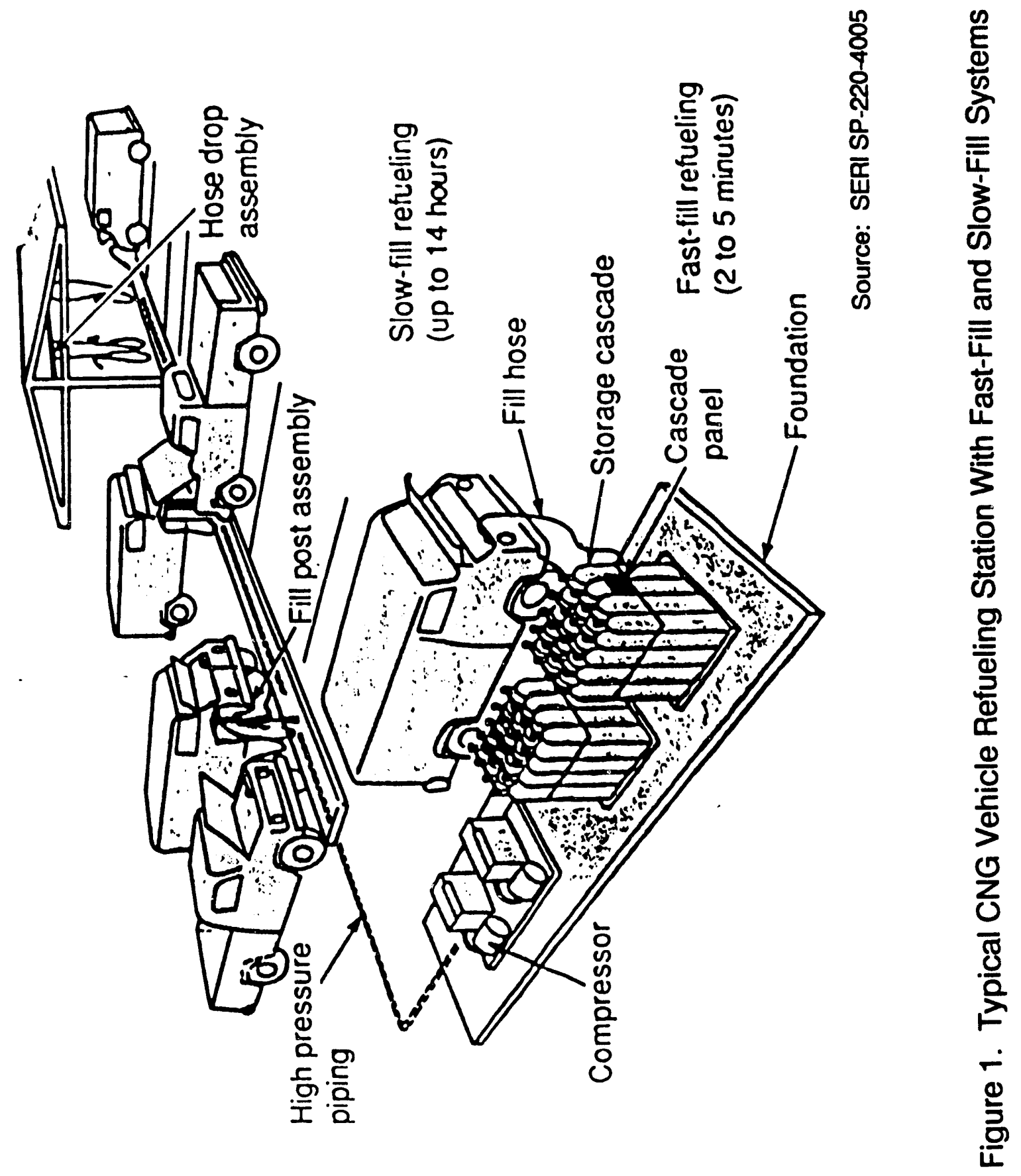




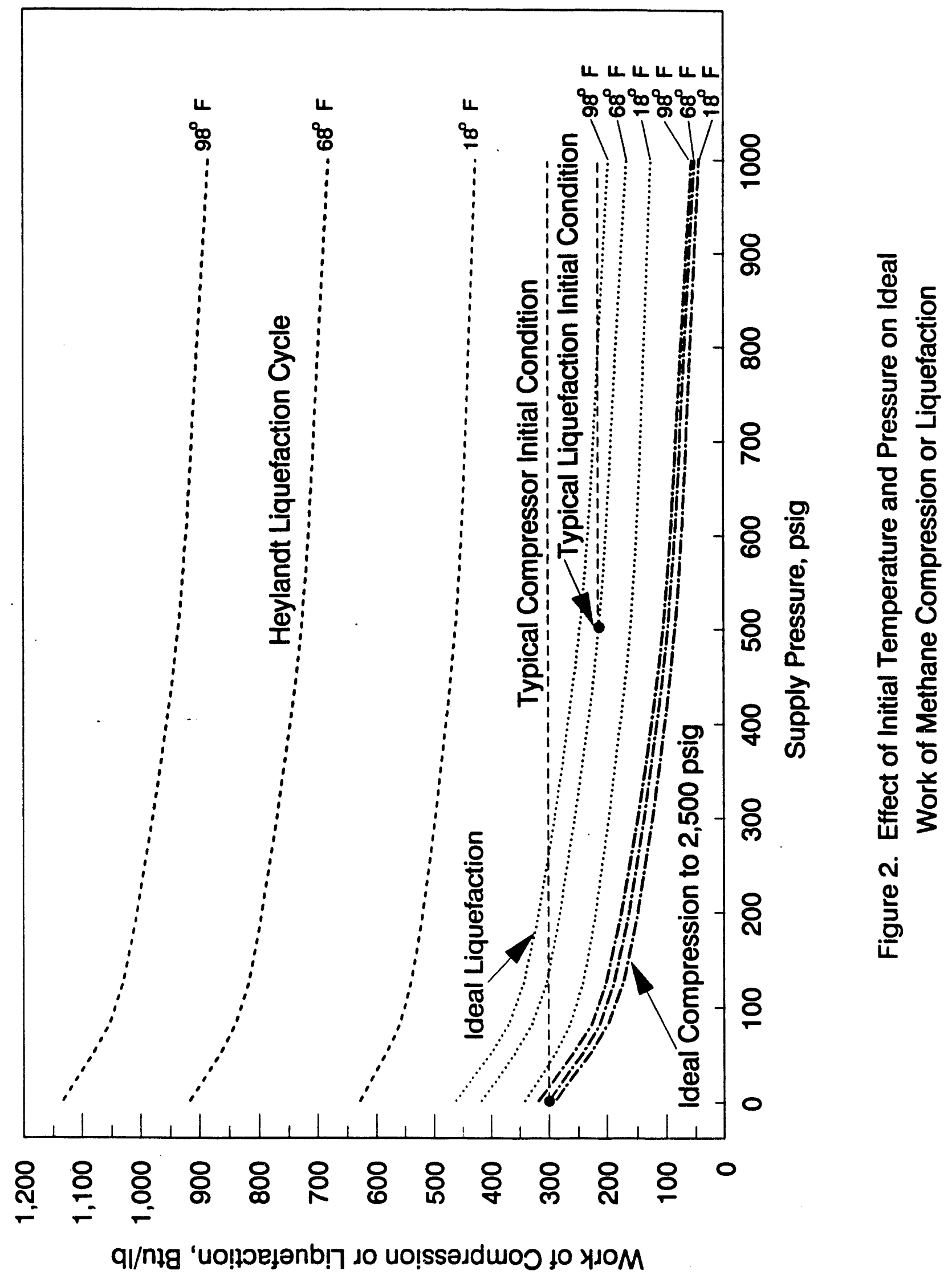


condition might be $500 \mathrm{psi}$ at $68^{\circ} \mathrm{F}$. Then, as indicated in the figure, the minimum theoretical work for liquefaction would actually be less than the minimum theoretical work for compressing CNG from the 5-psi supply pressure typical for a distribution system supplying retail CNG stations.

Unfortunately, liquefaction is not so simple. Actual turboexpanders have trouble handling liquid, so they must avoid the two-phase region. Practical liquefaction cycles are subject to a great deal of inefficiency because of the difficulty of creating low-temperature sinks with a continuous temperature range. As an example, Figure 2 shows the ideal work required (100\% efficient compressors and expanders) for the Heylandt cycle, a variation of the well-known Claude cycle. At 500-psi inlet pressure and $68^{\circ} \mathrm{F}$, the energy required is $720 \mathrm{Btu} / \mathrm{lb}$ or almost four times the minimum theoretical value. When real-world efficiencies are considered, the actual energy required can more than double again.

\section{Energy Usage in Practical Systems}

The technology of LNG production is still maturing (Figure 3). Large-scale multibillion dollar plants that produce LNG for export by ocean tanker now consume about $10 \%$ of the plant throughput, or about $2,000 \mathrm{Btu} / \mathrm{lb}$, in the production process $(14)$. However, liquefaction plant efficiency decreases markedly with plant size. Plant efficiency, calculated as percent of Carnot efficiency, varies with size as shown in Figure 4. A 36,000 gal/day plant utilizing a mixed refrigerant turboexpander configuration is estimated to cost $\$ 3.5$ million and use $16 \%$ of the inlet gas, or $3,400 \mathrm{Btu} / \mathrm{lb}$, in the production process $(2,16)$. Under development is a small-scale Stirling cryorefrigerator driven by a gas powered Stirling engine, designed to produce 50 gal of LNG per day while using $30 \%$ of the feed stream as process energy $(9)$.

The three data points for energy usage discussed above are plotted in Figure 5. In contrast to the situation for compression, where the small-scale, one-vehicle compressor uses only about twice as much energy as a large-scale system, the small-scale, one-vehicle liquefier uses four times as much energy as a large-scale system, and about $\mathbf{1 0}$ times as much as the theoretical minimum. It would seem that this is an area that could profit from increased research and development.

\section{Special Situations}

If natural gas is available at a pipeline pressure greater than about 500 psi at a pressure letdown point, a simple one-pass turboexpander can be used to liquefy part of the stream at essentially zero energy cost. At pressures above 500 psi, an isentropic expansion (an isentropic expansion is a reversible expansion in which work is done by the system, in contrast to an adiabatic expansion in which no heat or work is removed from the system) from normal ambient temperatures ends up in the two-phase region at low pressures. Thus, about 10 to $15 \%$ of the feed stream can be liquefied with no energy input, and the remaining $85 \%$ ends up as low-pressure gas, which can be put into the low-pressure distribution system $(2,5,11,21)$.

The total range of energy required for liquefaction thus ranges from zero for special situations, to more than $9,000 \mathrm{Btu} / \mathrm{lb}$ for small-scale applications. Obviously, every specific case will be different and will require an individual analysis to get a reliable comparison between LNG and CNG. The only general conclusion to be drawn is that the highly unfavorable energy efficiency of the smallest LNG systems means that LNG is less suited for small fleets and should become progressively more attractive as fleet size increases. Again, research and development on higher efficiency small-scale units seems justified.

\section{ENERGY USED FOR TRANSPORTATION}

A conceptual illustration of a large-scale LNG production, distribution, and utilization system is shown in Figure 6. Bulk LNG would likely be obtained from one of three possibilities: 


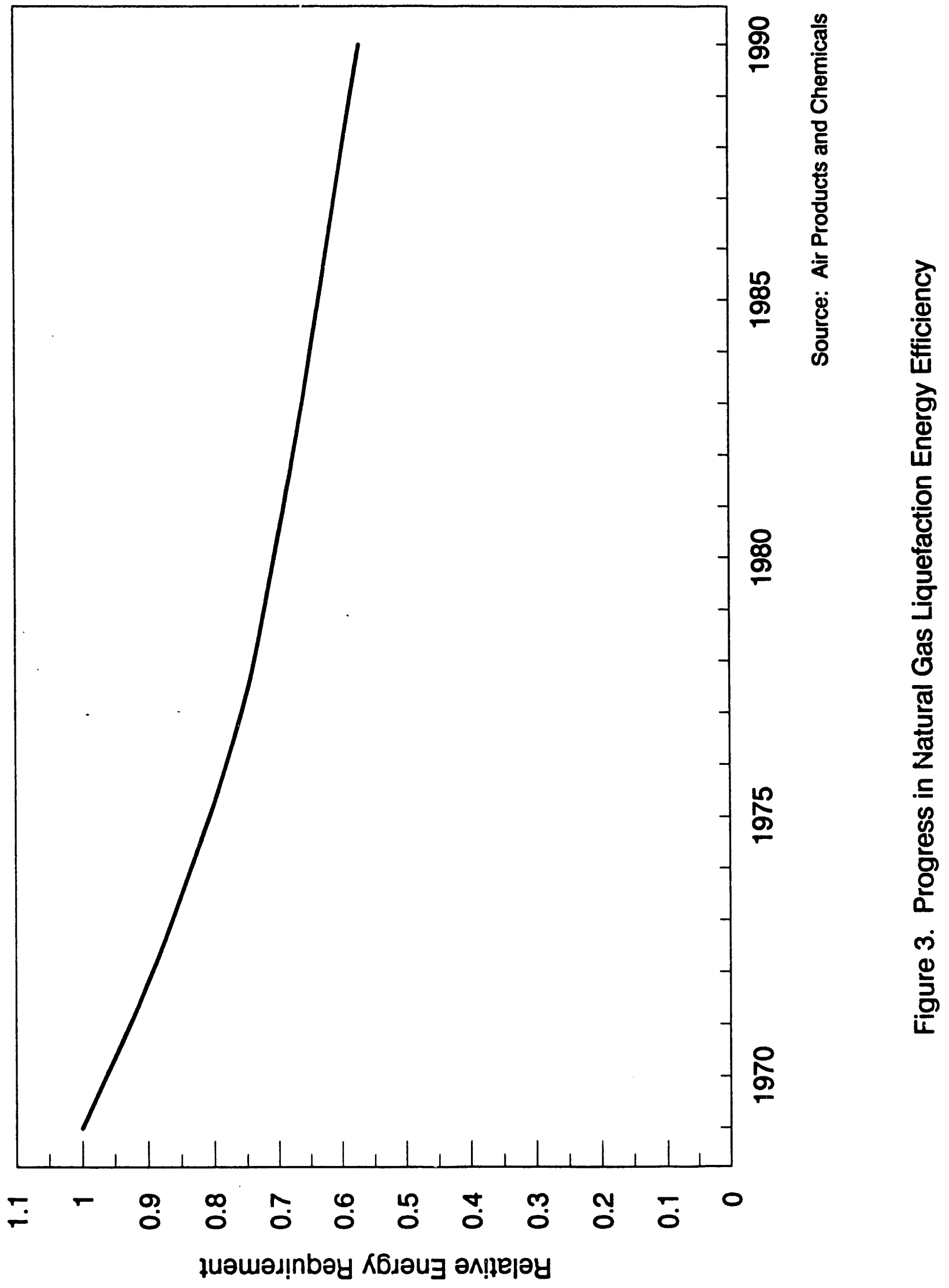




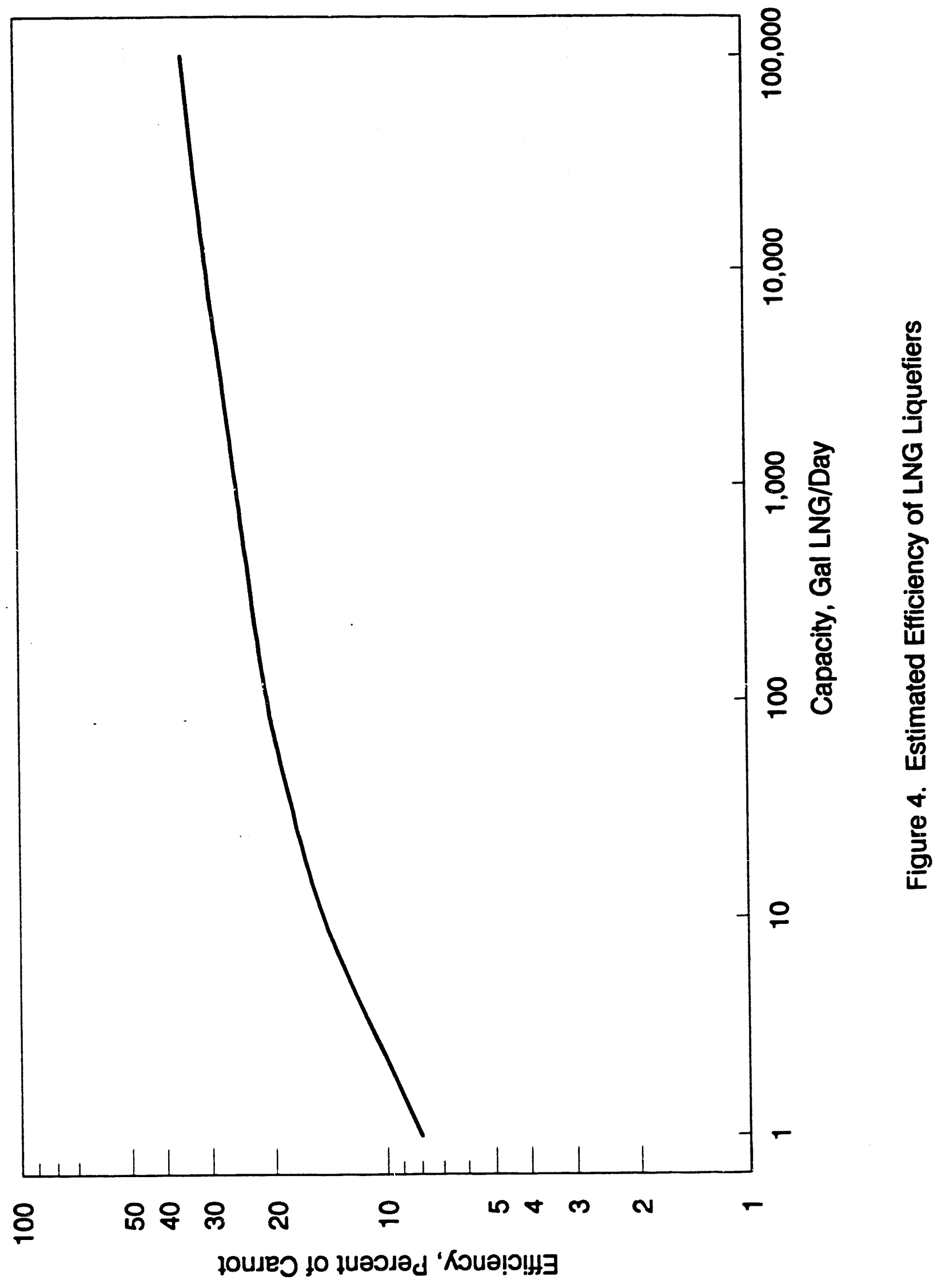




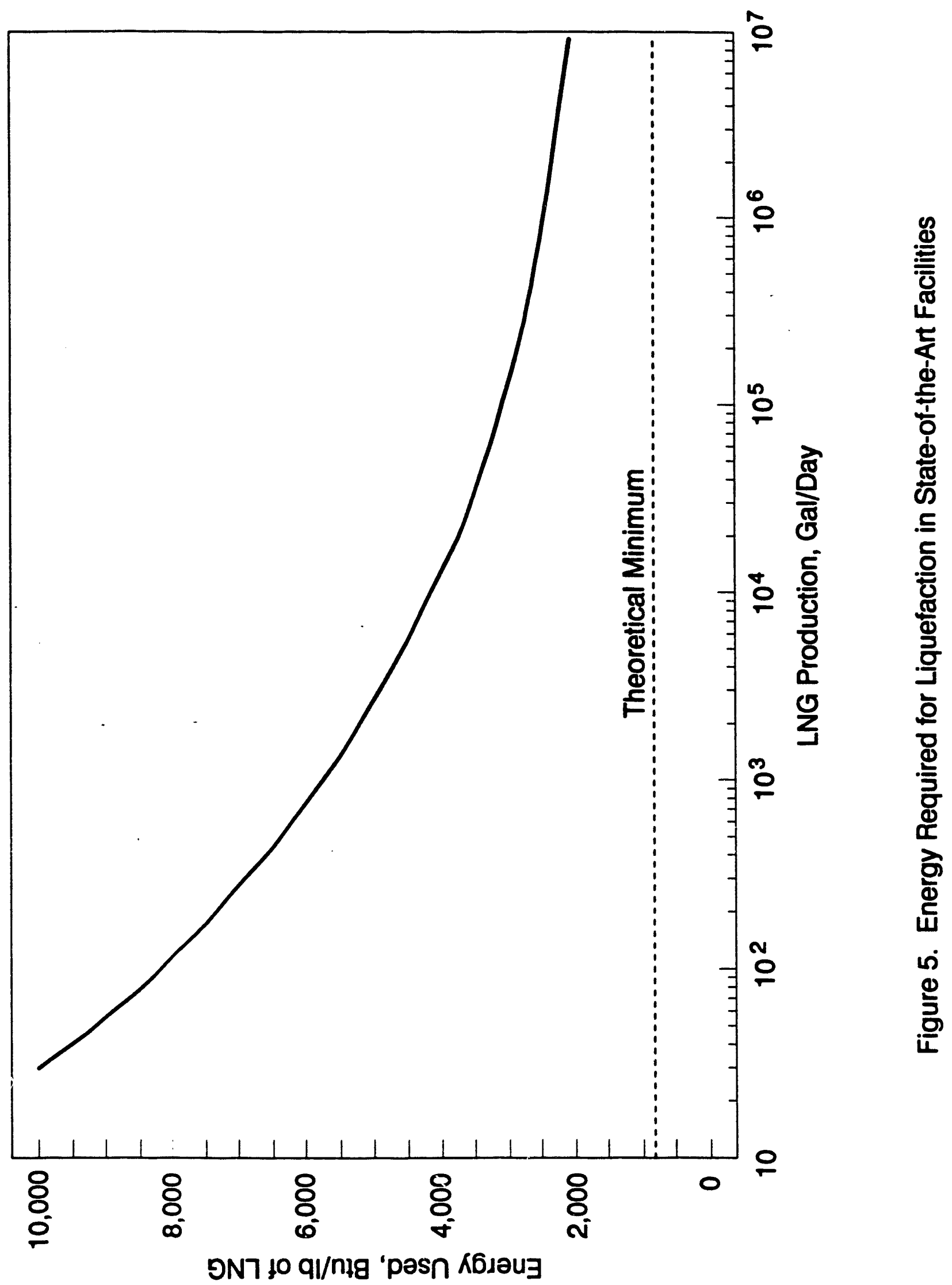




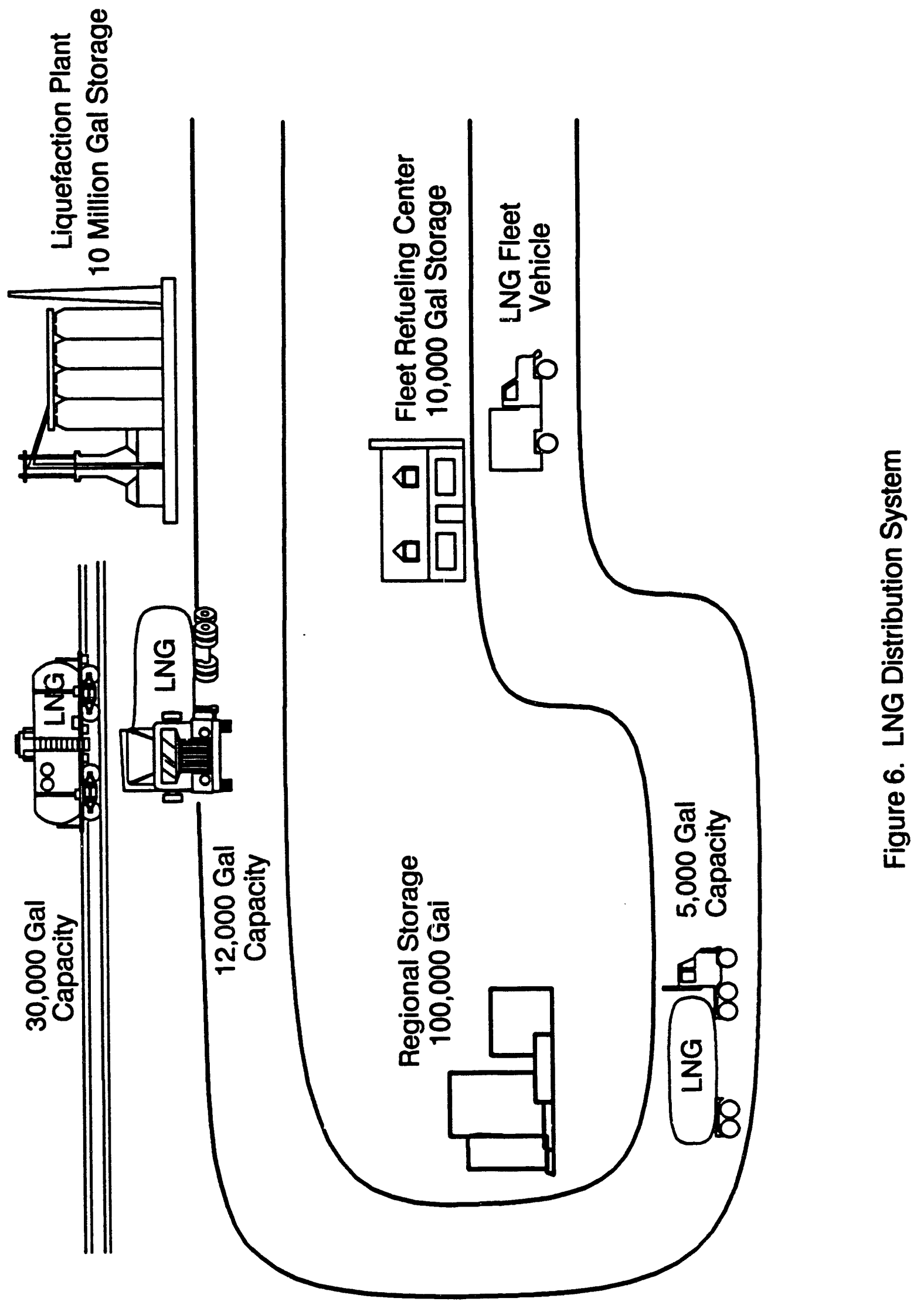


- An existing utility peak-shaving plant with large amounts of bulk storage

- A purpose-built liquefaction unit located with access to a high-pressure pipeline

- An overseas import terminal.

Such locations are likely to be some distance from central city vehicle fleets. The map in Figure 7 shows the locations of existing peak-shaving plants, import terminals, and bulk storage facilities.

If we consider that the energy required to compress gas to 500 psi is about $60 \%$ of that to compress it to 2,500 psi, using Figure 2 and a compressor efficiency of $75 \%$, we would compute a compression cost of $250 \mathrm{Btu} / \mathrm{lb}$. The average energy cost for intercity trucking is about 3,400 Btu per ton-mile ${ }^{(6 a)}$, so it would be possible to ship LNG about 150 miles in order to take advantage of a 500-psi supply pressure. It is assumed that this would usually be done. Because CNG fleet refueling compressor stations will be located at the endpoint of the supply system, economic calculations are based on supply at that point. Therefore the energy required to transport LNG from the liquefaction plant to the LNG fleet refueling center (assumed to be 150 miles apart) will be an energy requirement with no analogy in the CNG system, amounting to about $1.2 \%$ of the LNG energy content.

\section{VEHICLE REFUELING TIME}

A key characteristic for alternative fuel systems is the vehicle refueling time required. For overnight slow-fill systems, this is not an issue, because the labor hours to hook up and uncouple the system are the same whether it then takes $1 \mathrm{~h}$ or $8 \mathrm{~h}$ to fill the tank. For fast-fill systems, however, especially those refueled by drivers during the day, refueling time has great economic importance. Time spent refueling is "unproductive" time, creating no income for the enterprise. Thus driver time spent in refueling carries a "lost opportunity" cost, which may not be accounted for in the usual energy and economic analyses. If a driver's labor plus overhead rate in a company is $\$ 30 / \mathrm{h}$, an extra $10 \mathrm{~min}$ consumed in refueling carries an opportunity cost of $\$ 5.00$. If the average fill is 20 gal of diesel fuel equivalent, the lost opportunity cost because of extra refueling time is $\$ 0.25 / \mathrm{gal}$, a significant fraction of fuel cost.

This study found insufficient data in the literature to decide whether LNG or CNG had a significant advantage. There are references to projected fill times of as little as 5 min for both $\mathrm{CNG}^{(10,20,25)}$ and $\mathrm{LNG}(20)$. At the same time, there are anecdotal references to much longer fill times being required.

Because it is in the liquid phase, a greater mass of LNG can flow through a fill pipe of given size at a given pressure drop than can CNG. However, there is no particular reason to use the same pipe size and pressure drop in both cases. LNG faces a handicap if the tank being filled must first be cooled to any extent. Then the rate of fill is constrained by the rate at which boiloff vapors can be recycled to the storage system.

Fast-fill CNG systems also have a problem caused by the heating effect when the gas in the vehicle tank is compressed and thereby heated. This temperature rise makes it impossible to put as much mass in the tank as can be done with a slow-fill system. The penalty may be as much as 5 to $10 \%$ of tank capacity.

Although the liquid state of LNG has inherent advantages for fast fueling, the cryogenic nature of LNG creates other problems that probably even out the comparison. Fast-fill CNG systems may be capable of being made fast enough that no significant advantage is possible for LNG.

A hybrid system has also been proposed in which LNG is vaporized and supplied to a CNG system $^{(10,11)}$. This approach avoids the cost of a fast-fill compressor, but unless LNG is available at nearly the same cost, it probably would not be justified on the basis of refueling economics alone. 


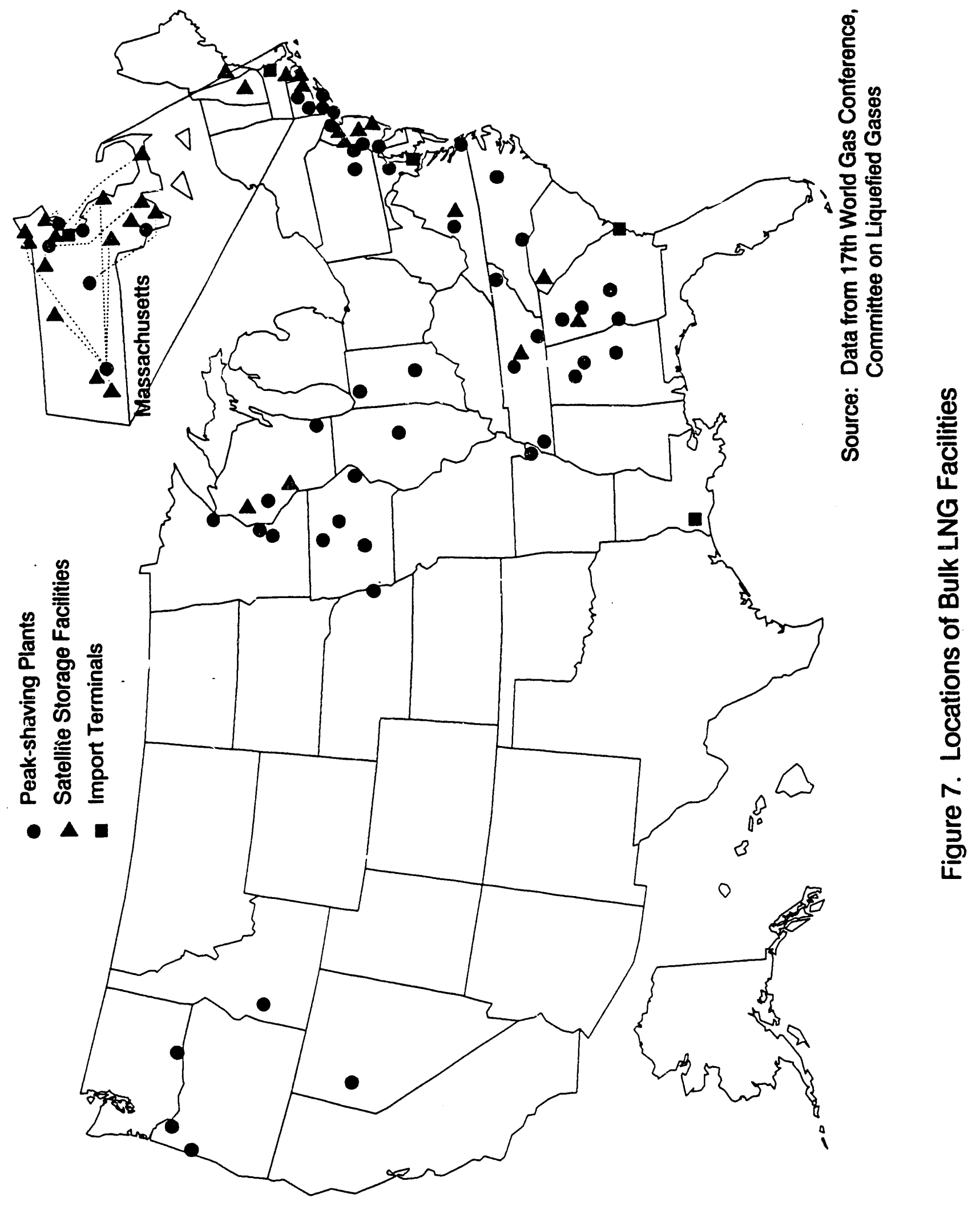




\section{COMPARISON OF END-USE CHARACTERISTICS}

\section{POTENTIAL ADVANTAGES OF LIQUID FUEL}

In this section it is assumed that dedicated-fuel engines will be designed for optimum performance with either CNG or LNG. After natural gas has been heated to ignition temperature in an engine, there is no way to determine whether it was originally carried on the vehicle as LNG or CNG, and the combustion process will be the same for either. In either case, all carbon atoms will eventually be converted to carbon dioxide, making an equal impact on the greenhouse effect. The only way that the use of LNG can affect engine operation is with respect to physical effects arising from its temperature and liquid state. In most current LNG engine designs, part of the fuel may be drawn from the vapor phase and the liquid is sent through a heat exchanger and vaporized before being drawn into the engine. Thus no attempt is made to utilize the potential advantages of a liquidphase fuel.

Theoretically, the use of LNG would make it possible to design an engine with direct injection of liquid natural gas into the cylinders. Several benefits could result. First, by not mixing gaseous fuel with the air charged to the cylinder, a greater mass of air can be inducted without using some method of supercharging. Although engine power is an important issue with natural gas conversions, it is less significant when considering optimized designs because the engine can simply be made larger if more power is desired.

Second, higher compression ratios can be used without problems of preignition.

Third, direct injection makes it possible to eliminate the use of a throttle for mixture ratio control, and thus eliminate the efficiency loss caused by pressure drop across the throttle.

Fourth, the injection of cold liquid will lower peak combustion temperatures and reduce $\mathrm{NO}_{\mathbf{x}}$ emissions.

Although these potential benefits are well known, the practical difficulties of achieving direct injection of a cryogenic liquid into a hot engine have been insuperable to date. It is not clear that further research and development would be likely to be successful.

\section{POTENTIAL ADVANTAGES OF COLD FUEL}

Even if it cannot be maintained in the liquid state through the process of injection into the engine, there are numerous ways in which the cryogenic temperature of LNG can be made useful. These include:

$$
\begin{array}{ll}
\text { - } & \text { Charge-air cooling } \\
\text { - } \quad \text { Cargo cooling } \\
\text { - } \quad \text { Aussenger air conditioning } \\
\text { - } \quad \text { Auxiliary power. }
\end{array}
$$

\section{Benefits of Charge-Air Cooling}

If liquid natural gas is mixed directly with the air intake stream immediately in front of the intake valves, the heat of vaporization of the liquid plus the initial temperature of approximately $-162^{\circ} \mathrm{C}$ will cause a significant cooling of the air stream. There are several benefits to charge-air cooling. First, the greater density of the cooler air results in a greater mass of fuel/air mix being charged to the engine and more power from a given engine size. 
Second, the lower charge-air temperature decreases the thermal load on the engine, that is, the amount of heat that must be removed to keep the engine below its high-temperature operating limit.

Third, a lower charge-air temperature results in a lower peak cylinder temperature, which should decrease the amount of nitrogen oxide in the exhaust. For heavy-duty compression ignition engines, $\mathrm{NO}_{\mathrm{x}}$ emissions may limit future performance. For example, the use of a lean-burn engine strategy greatly improves the thermal efficiency of an engine but renders an $\mathrm{NO}_{x}$ reduction catalyst useless, making low engine-out $\mathrm{NO}_{\mathrm{x}}$ emissions critical. A typical curve of steady-stat engine-out NO emissions for a heavy-duty engine as a function of measured peak cylinder temperature ${ }^{(17)}$ is shown in Figure 8. Also shown in Figure 8 is the 1991-1994 federal standard for NO emissions in the Environmental Protection Agency (EPA) transient cycle test. The use of LNG for charge-air cooling should reduce the charge-air temperature by about $45 \mathrm{~K}$ and the peak combustion temperature by about $35 \mathrm{~K}$. As seen in Figure 8 , this could conceptually have the effect of reducing $\mathrm{NO}_{\mathrm{x}}$ emissions by about $0.9 \mathrm{~g}$ /horsepower-hour, or by about $18 \%$. This, of course, could be a very valuable result, even though this effect alone would not make it possible to meet stringent 1995 and later $\mathrm{NO}_{\mathrm{x}}$ emission standards. Note that emissions in the transient cycle test are not the same as steady-state emissions, and the relative effect shown in Figure 8 may not be the same for certification emissions.

The calculated temperature effect shown in Figure 8 is based on a stoichiometric air/fuel ratio. In a lean-burn engine, more air is used per pound of methane and the reduction in peak combustion temperature would be proportionately less than that shown in Figure 8.

\section{Joule-Thompson Cooling with CNG}

It has been suggested that some of the benefits of charge-air cooling could also be achieved with CNG, by making use of the Joule-Thompson (J-T) cooling effect, which occurs when the highpressure gas in the vehicle tank expands through a pressure-regulating valve or an injector on its way to the engine. However, the magnitude of cooling obtainable from the J-T effect is much smaller and is highly variable. The effect of J-T cooling is sometimes counter-intuitive. The J-T coefficient can be zero or even negative, causing heating rather than cooling during adiabatic expansion (although not in the range of interest for methane in CNG vehicles). For typical CNG vehicle conditions, a J-T expansion from 500 psi to 5 psi would cool the methane by as little as $16^{\circ} \mathrm{C}$. Expanding from $2,500 \mathrm{psi}$ at $20^{\circ} \mathrm{C}$ to 5 psi would result in a cooling of $100^{\circ} \mathrm{C}$. This cooling would increase to $116^{\circ} \mathrm{C}$ if starting from $-17^{\circ} \mathrm{C}$, and decrease to $66^{\circ} \mathrm{C}$ if starting from $38^{\circ} \mathrm{C}$. Thus the amount of cooling obtainable decreases as the ambient temperature increases, whereas from the engine standpoint more cooling is needed as the temperature increases.

The J-T cooling of methane, when mixed with the stoichiometric amount of air at 17.3 to 1.0 mass ratio, would result in a net charge-air cooling of as little as $3^{\circ} \mathrm{C}$ to as much as $15^{\circ} \mathrm{C}$, compared to a constant $45^{\circ} \mathrm{C}$ for LNG. The available J-T cooling, of course, disappears as the tank approaches empty.

Even if the latent heat of vaporization of LNG is not used, and a fuel vaporizer is installed, the cold methane vapors could provide a constant charge-air cooling of $20^{\circ} \mathrm{C}$, compared to the smaller and more variable amount of cooling available from J-T expansion.

\section{Cooling Efrect in Spark-Ignited Engines}

For spark-ignited engines, charge-air cooling cuuld make it possible to raise the knock-limited compression ratio, thus increasing power and efficiency while keeping maximum temperature and NO constant. This hypothetical effect is shown conceptually in Figure 9. A charge-air cooling of $20^{\circ} \mathrm{C}$ is illustrated, representing the maximum amount of cooling that could be obtained if a fuel vaporizer is used upstream of the mixing point. Direct mixing of LNG with the charge air would more than double the cooling effect. 


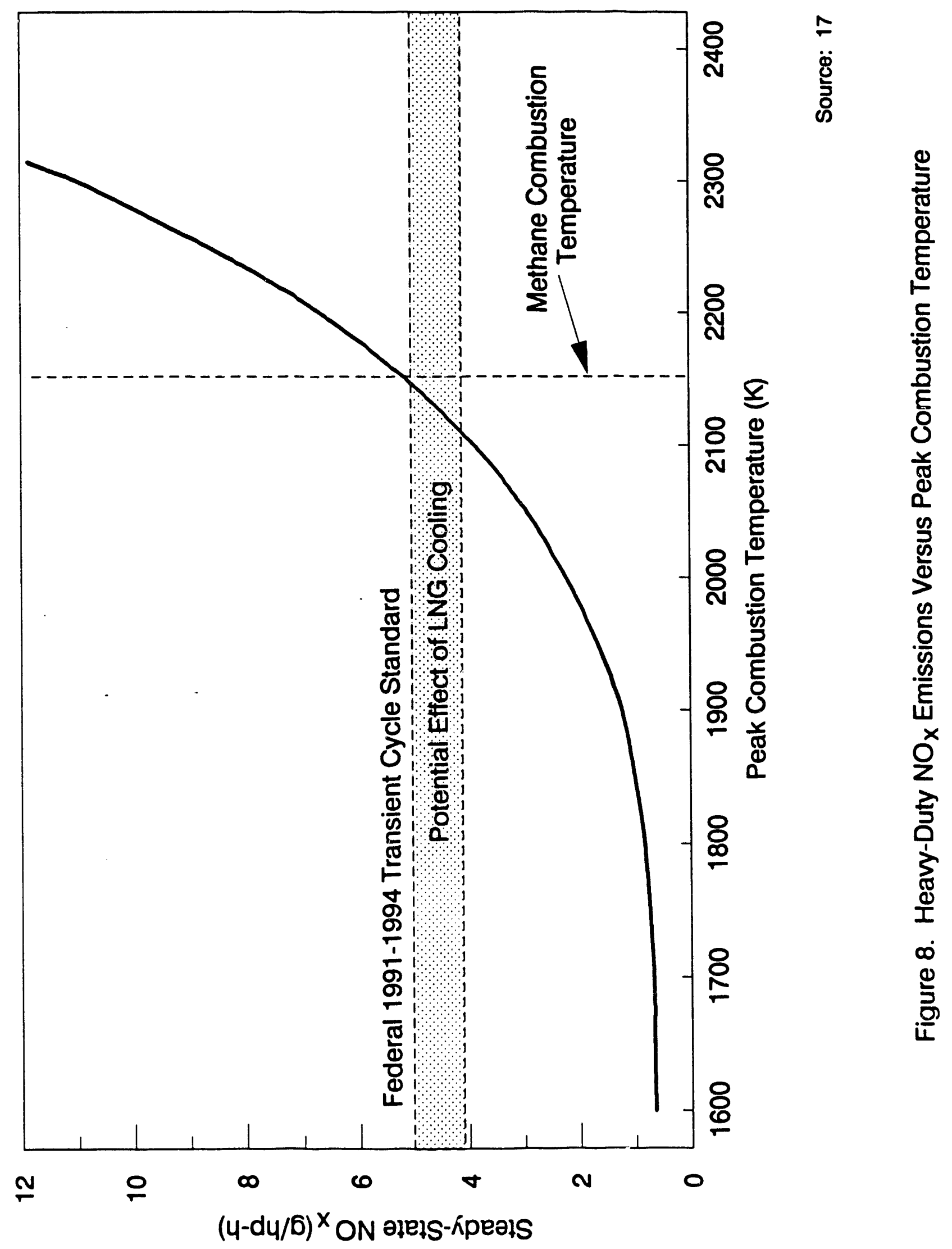




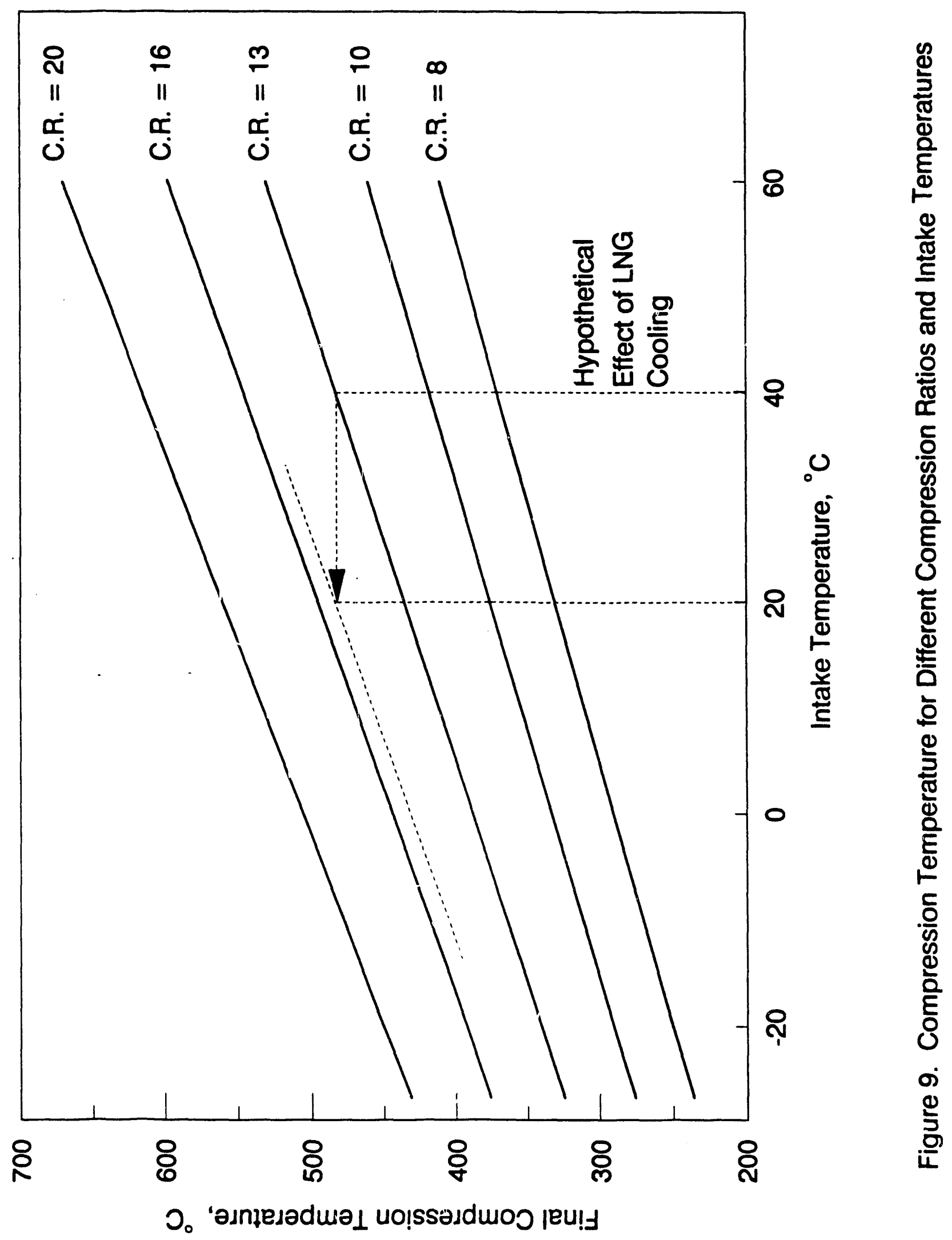


The line shown in the figure for effect of LNG cooling assumes that the knock-limited compression ratio is a function only of the final compression temperature. This is not true, but the general direction of the effect should be correct. As seen in the figure, the effert of charge-air cooling could be to make possible a compression ratio increase from 13 to over 15 . This would yield a theoretical increase of $2 \%$ to $3 \%$ in engine efficiency. Actual gains could be smaller because engine friction losses increase with increasing compression ratio.

If direct injection of LNG into the air stream is used, the effect could be significantly greater.

\section{Non-Engine Uses for Cryogenic Methane}

As noted earlier, there are a number of non-engine-related ways in which the use of LNG could provide benefits for commercial vehicles not obtainable with CNG. It would be technically feasible to use LNG cold for passenger air conditioning, but because this is a highly variable load, and because this study is not concerned with automobiles, that possibility was ignored. It may have possibilities for buses, however.

Two other major possibilities exist. One is to provide refrigeration for cargo cooling, and the other is to provide auxiliary power. In the area of cargo cooling, considerable research has been carried out on the use of LNG in shrimp boats, $(1,4)$ and the use of LNG cold to cool the catch. In the shrimp boat tested, the vessel carried 5,100 gal of LNG to provide $80 \%$ of the fuel for a 21-day cruise. At full fuel flow, the LNG flow to the main engine could provide up to 3 tons of refrigeration capacity. This was enough to maintain the catch at a constant $-23^{\circ} \mathrm{C}$ after freezing, although it was not enough to supply peak load demands for initial freezing. Similar applications in refrigerated trucks can be visualized.

In the area of auxiliary power, an LNG-powered aircraft has been described ${ }^{(19)}$, which uses the energy obtainable from the physical state of the fuel to provide auxiliary power. The scheme is shown in Figure 10. The LNG is vaporized and heated with engine exhaust gases, then expanded through a turbine that provides auxiliary mechanical and electrical power. Similar applications can be easily visualized for locomotives and boats running on LNG, but are less likely for trucks and buses. 


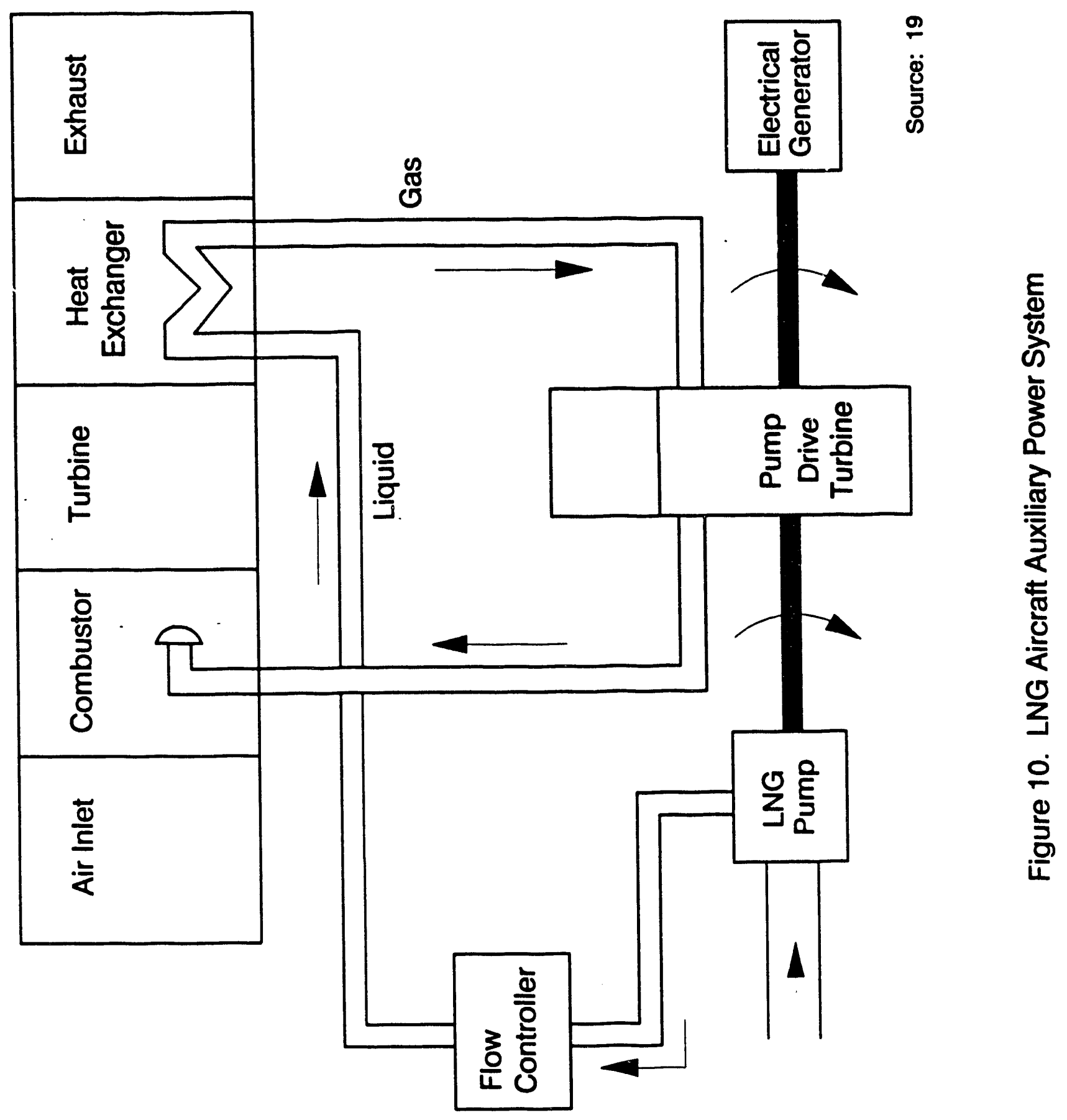




\section{RELATIVE EFFECTS OF TANK WEIGHT}

\section{TANK WEIGHT VERSUS VOLUME}

The most obvious and usually the most important distinction between CNG and LNG vehicle systems is in the fuel tanks. CNG tanks must be both larger and heavier to hold the same mass of fuel as an LNG tank. And LNG tanks must be both larger and heavier than diesel or gasoline tanks to hold the same energy equivalent.

It is unquestionable that LNG tanks involve less weight and volume when large fuel quantities are required. However, there are conflicting data and speculation in the literature about the exact relative weights. One reason, of course, is that different manufacturers using different designs will come up with different tank weights per unit of internal volume. Another is that several different tank materials may be used for CNG tanks, ranging from ordinary steel, to fiberglass-wrapped steel, fiberglass-wrapped aluminum, and, perhaps eventually, all-composite carbon fiber tanks.

This study does not attempl an engineering analysis to estimate the precise weights of various sizes and types of tanks. Rather, a broad review of the literature $(3,7,8,12,13,14,15,21,23,24)$ was used to develop some approximate tank weight versus volume relationships for use in drawing general overall comparisons of CNG versus LNG in heavy-duty applications.

One conjectured advantage of LNG tankage is a better economy of scale. Because of material stress considerations, CNG tanks are generally available as relatively small-diameter cylinders. When more fuel volume is needed, more cylinders are added in a modular fashion. Thus, there is no change in tank weight per unit volume regardless of vehicle fuel needs. A plot of tank weight versus volume would be a straight line.

In the case of LNG, however, it is feasible to keep increasing unit tank size. Because internal volume increases as the cube of the diameter of a sphere, while the surface area increases only as the square, a tank's weight should increase only approximately as the two-thirds power of the internal volume. Although this is theoretically the case, for actual tanks below 150-gal capacity, the weight versus.volume curve appears to be nearly linear, and up to the largest sizes considered in this study, the use of an exponent of two-thirds instead of one did not make a significant difference with respect to the data scatter.

To approximate the tank weight ratios for different fuels, a set of straight lines was used, as presented in Figure 11. Because LNG tanks are double-walled, they would be expected to weigh at least twice as much as diesel fuel tanks. Because they must also withstand some internal pressure and be insulated, the actual weight ratio is nearer to 3 to 1. From Figure 11, a rough rule-of-thumb would say that LNG tanks are three times as heavy as diesel tanks; carbon composite CNG tanks, if perfected, would be twice as heavy as LNG tanks; and state-of-the-art aluminum/fiberglass CNG tanks are three times as heavy as LNG tanks.

\section{TANK VOLUME NEEDED FOR HEAVY-DUTY TRUCKS}

In order to calculate the effects of tank weight when switching from diesel fuel to LNG or CNG, it was first necessary to estimate the amount of fuel required. This depends on the rate of consumption, gallons per mile, and on the maximum vehicle range required. Data for average truck fuel consumption as a function of gross vehicle weight rating were obtained from the Transportation Energy Data Book ${ }^{(6 a)}$ and are plotted in Figure 12. Note that the X-axis is weight rating, not actual on-the-road weight when the mileage data were obtained. These data are from a survey and simply represent the average response to a question about fuel mileage. Some assumption must be made about the actual loaded weight at which the mileage was obtained--it could be anywhere between the empty weight (also called curb weight or tare weight) and the maximally loaded weight (gross vehicle weight rating). 


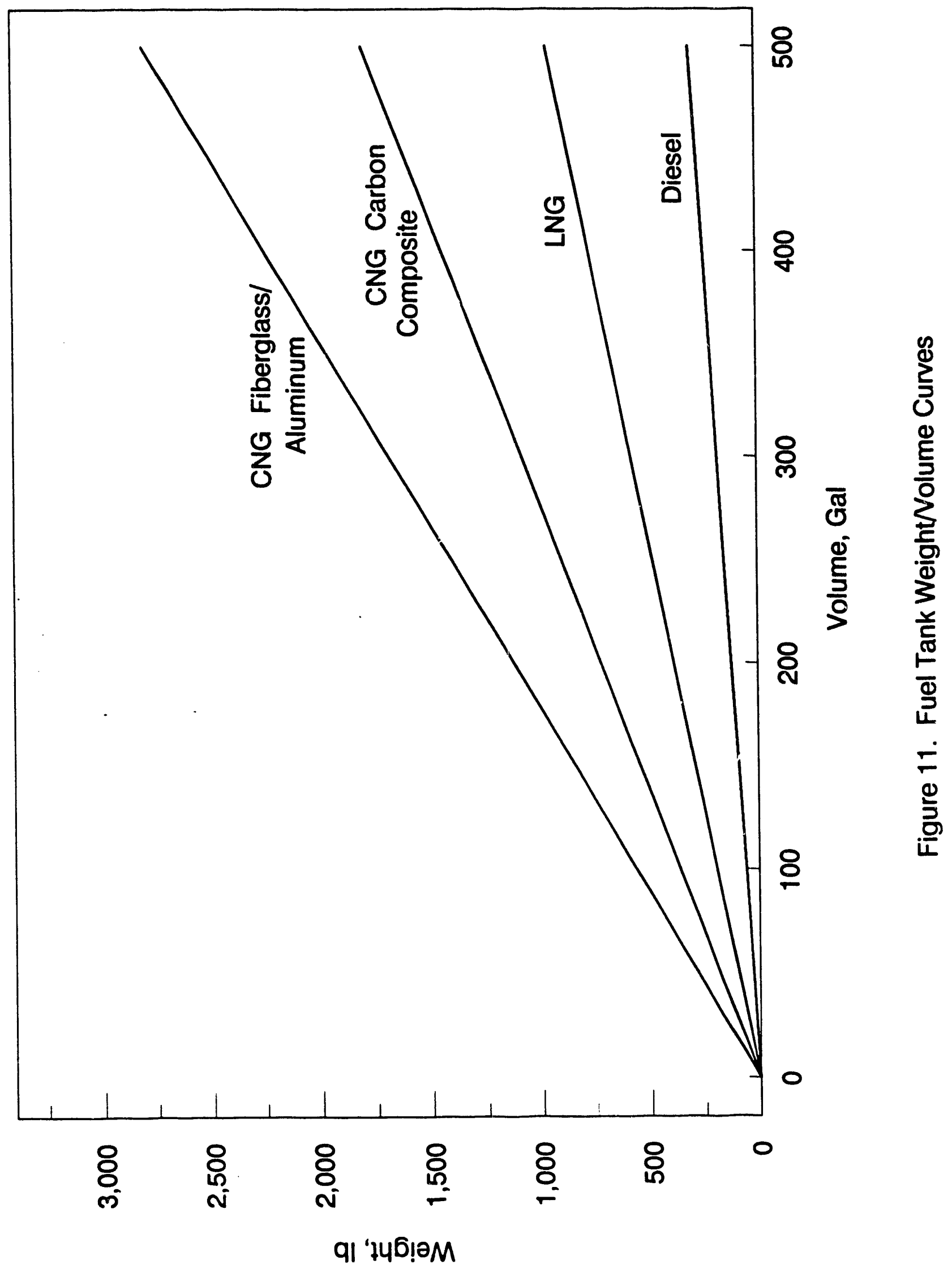




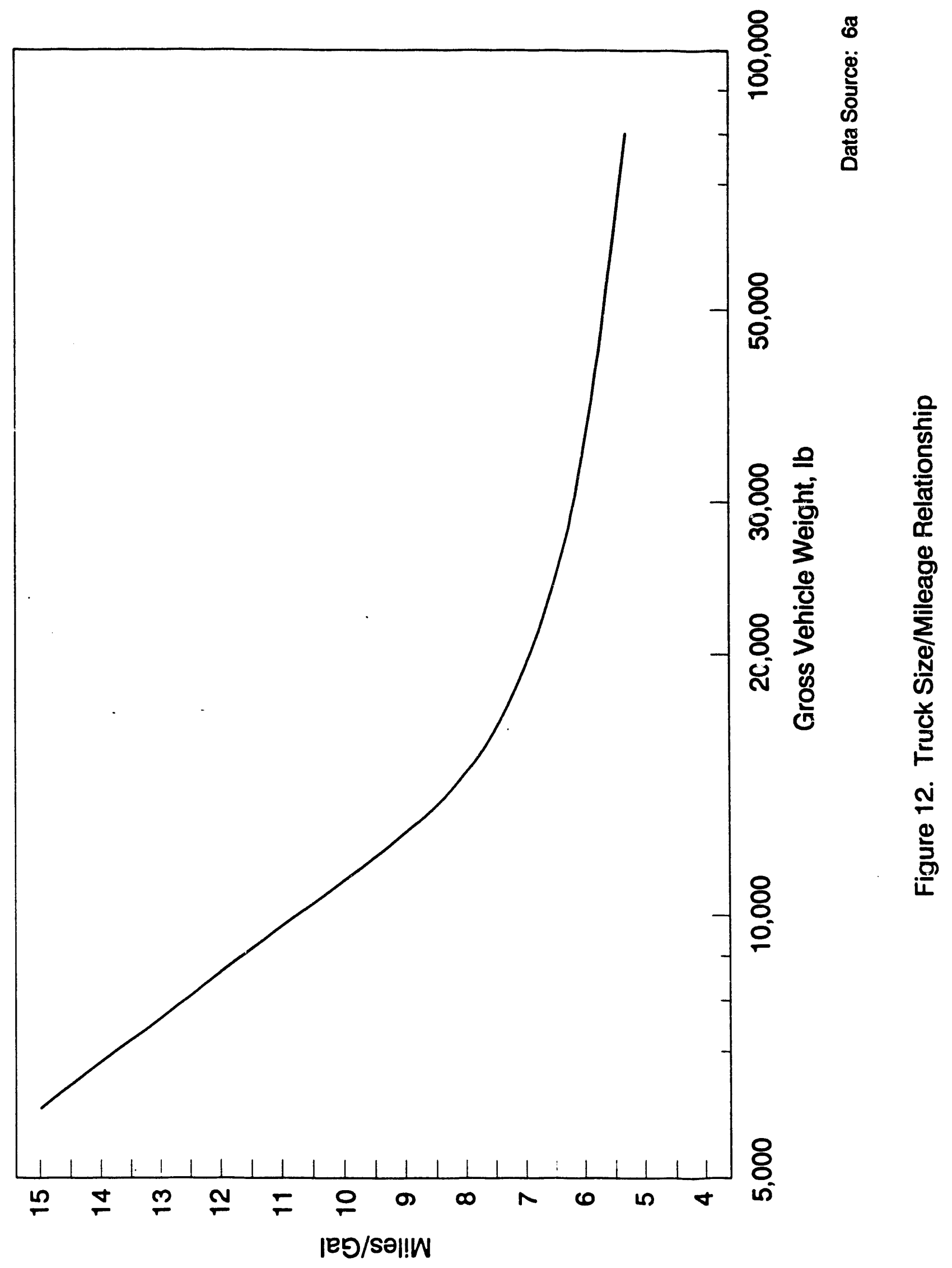


Figure 13 shows the typical relationship between empty vehicle weight and gross vehicle weight (GVW). The difference between these two parameters is the maximun payload weight. For purposes of this analysis, it was assumed that the mileage data in Figure 12 apply to a vehicle loaded with $50 \%$ of its maximum payloac. There are no data available to substantiate or to refute this assumption.

To compare tank weights required for LNG and CNG, it is necessary to estimate the volume of fuel required to travel an equal distance in a vehicle of the same weight. This factor depends on the assumed efficiency of diesel versus natural gas engines as well as the energy densities of the fuels. Data in this area are sparse. However, a precise estimate of this factor is not especially important for this analysis as long as it is derived in the same way for both LNG and CNG. Therefore, the analysis was conducted using the factors from Battelle $(21,22)$, which result in 1 gal of diesel fuel being the equivalent of $1.89 \mathrm{gal}$ of LNG and $4.15 \mathrm{gal}$ of CNG. Using these relationships along with Figures 11,12 , and 13 , a set of truck weight/mileage relationships was developed as shown in Figures 14 and 15.

\section{CNG VERSUS LNG COMPARISONS}

As diagrammed in Figure 14, these figures can be used to determine the loss in fuel efficiency and paylosd if CNG is used instead of LNG. In the example, a truck with a GVW rating of $16,000 \mathrm{lb}$ and a required range of 500 miles is studied. First, point $F$ on the GVW curve at 16,000 lb is determined and a horizontal line drawn. Then the distance $A B$ is the difference in tank weight between fiberglass-wrapped aluminum CNG tanks and LNG tanks for a $16,000 \mathrm{lb}$ GVW truck with a range of 500 miles. The maximum payload carried by this truck prior to conversion to CNG is the distance $A C$ and the maximum after conversion from $L N G$ to CNG would be the distance $B C$.

To calculate the effect on mileage, the $50 \%$ loaded curve is used. From point $D$, the distance $D E$ is plotted equal to $A B$. Then a vertical line is dropped from $E$ to point $G$ and the new miles per gallon figure read from the $Y$ axis.

A series of calculations based on Figures 14 and 15 yields the results shown in Figures 16, 17, 18 and 19. The potential loss in maximum payload when switching from LNG to CNG is seen in Figures 16 and 17 . It must be understood that this is only a potential loss, which will only affect vehicles operating at near their maximum GVW rating. For those trucks which do operate at near capacity, however, it can be seen that this is a very serious effect.

The increase in fuel efficiency that would occur as a result of decreased tank weight when switching from CNG to LNG is given in Figures 18 and 19. This effect will be felt at all times, whether fully loaded or not, because the tank weights do not change once installed. An obvious and unsurprising conclusion arising from Figures 16 through 19 is that high-range trucks are much better off using LNG than CNG.

A perhaps less-anticipated conclusion is that smaller trucks would benefit much more from LNG than larger trucks (at equal range). This is because the extra weight of CNG tanks would displace a much greater fraction of maximum payload and would also have a greater depressing effect on the average miles per gallon.

An even less-anticipated conclusion is that payload effects may be just as important as mileage effects. Previous analyses have focused on the change in miles per gallon that results from the tank weights associated with different fuels. But if the vehicle is operated at near its maximum weight rating and must reduce payload because of tank weight, this affects the energy use per ton-mile more strongly than the change in miles per gallon. Furthermore, the two effects are additive. To assess the national implications of the payload effect, much more analysis would have to be carried out to estimate what fraction of heavy-duty vehicle mileage occurs in a region where payload would be affected by the difference between LNG and CNG tank weights. It is recommended that 


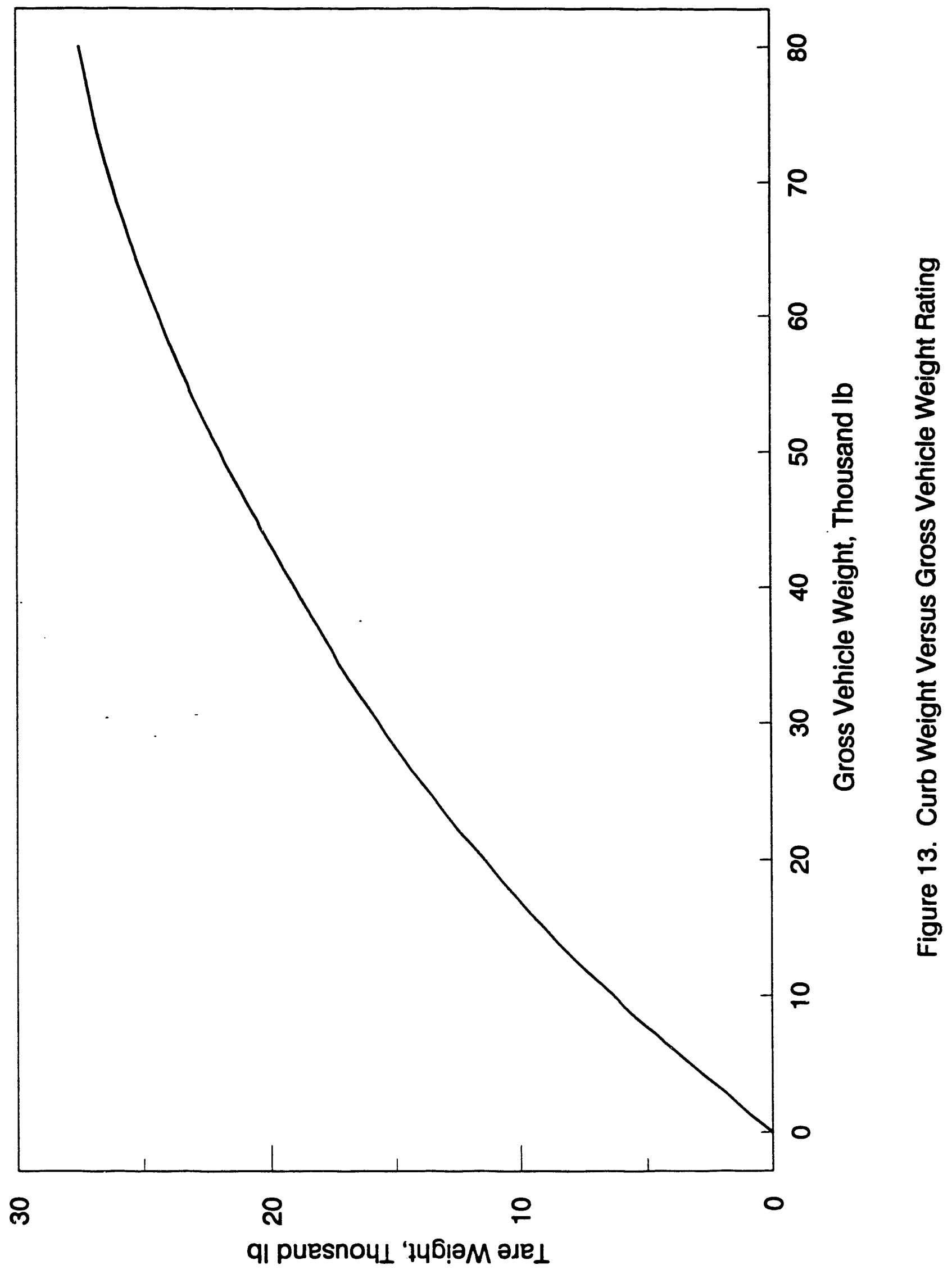




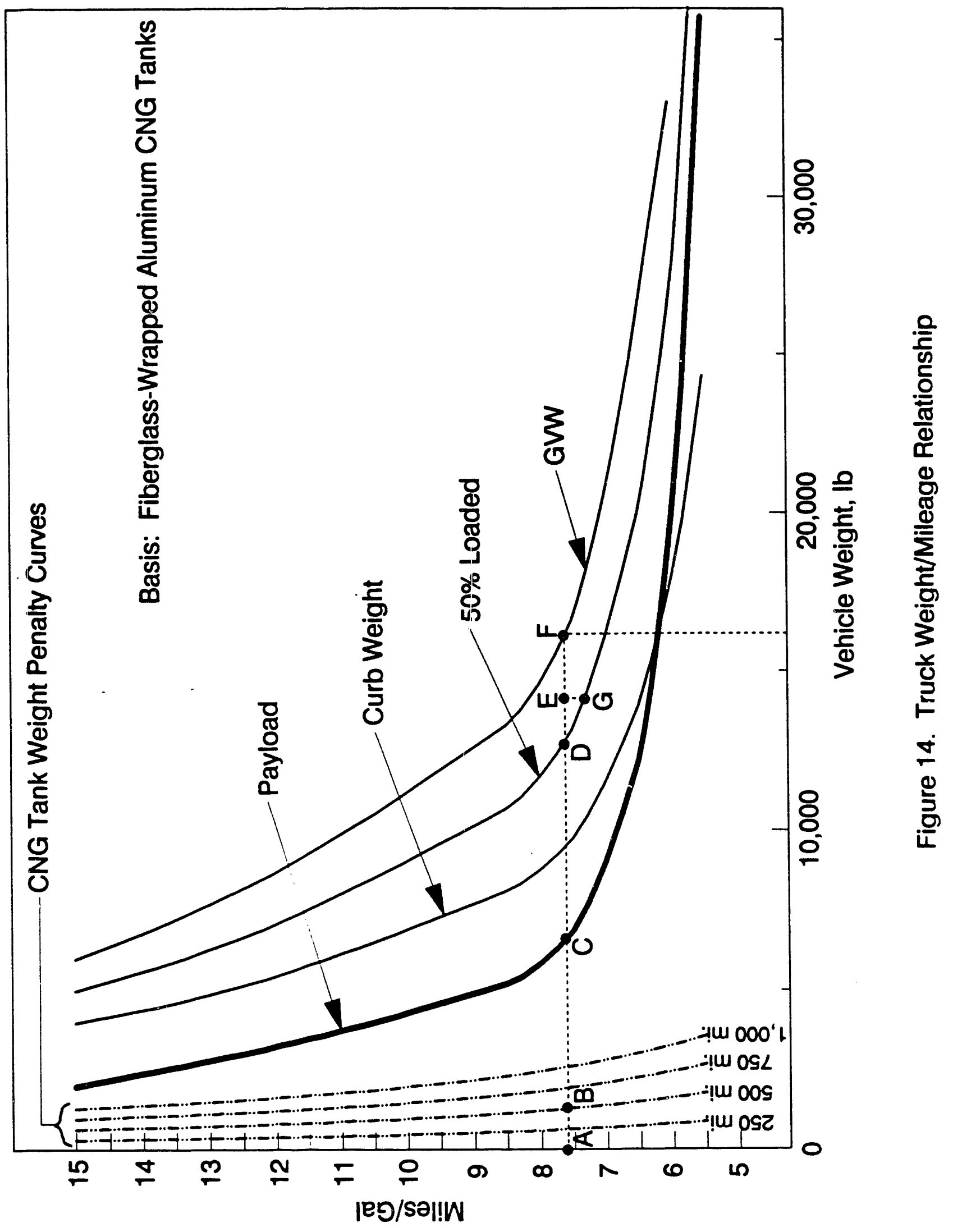




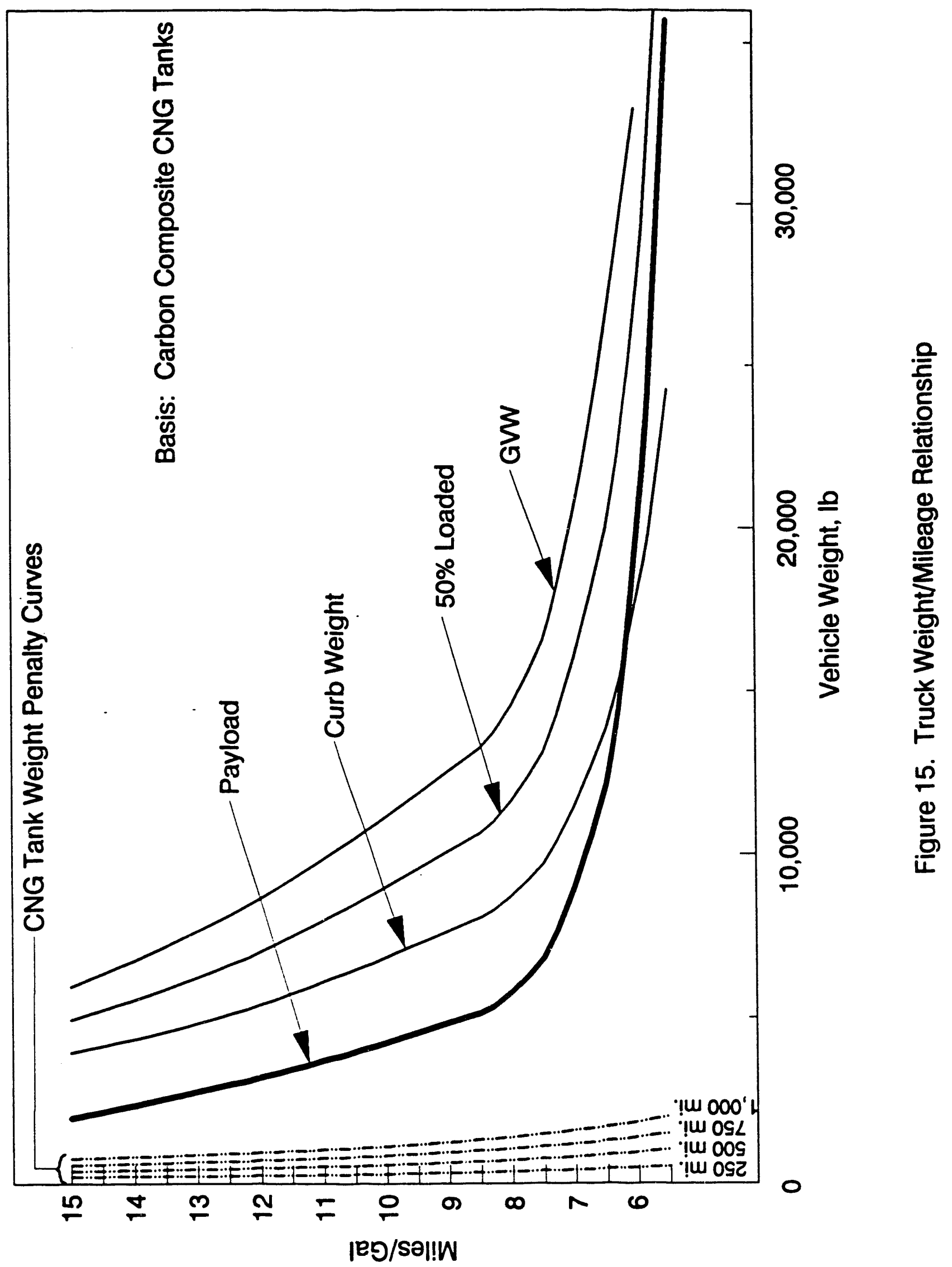




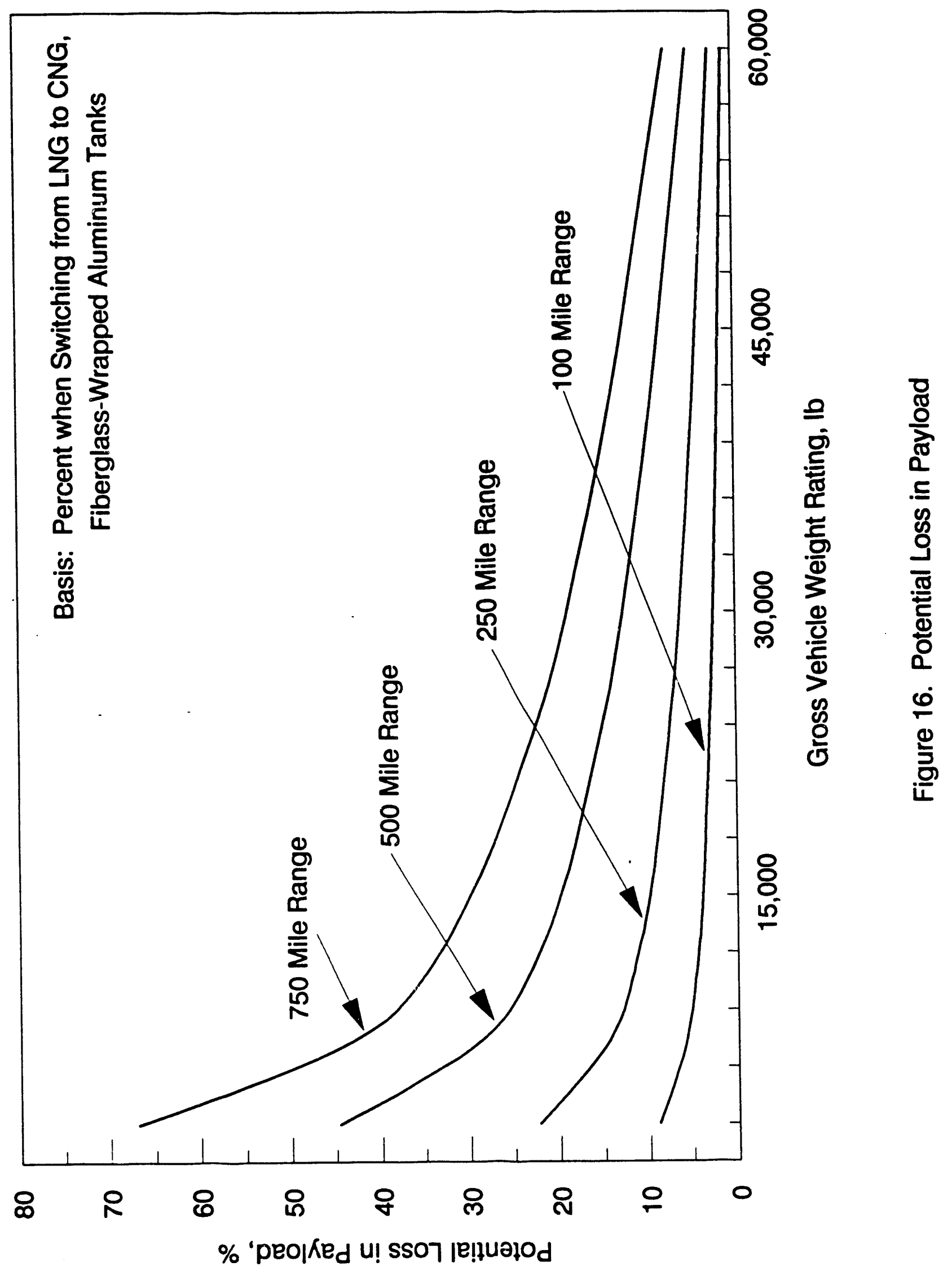




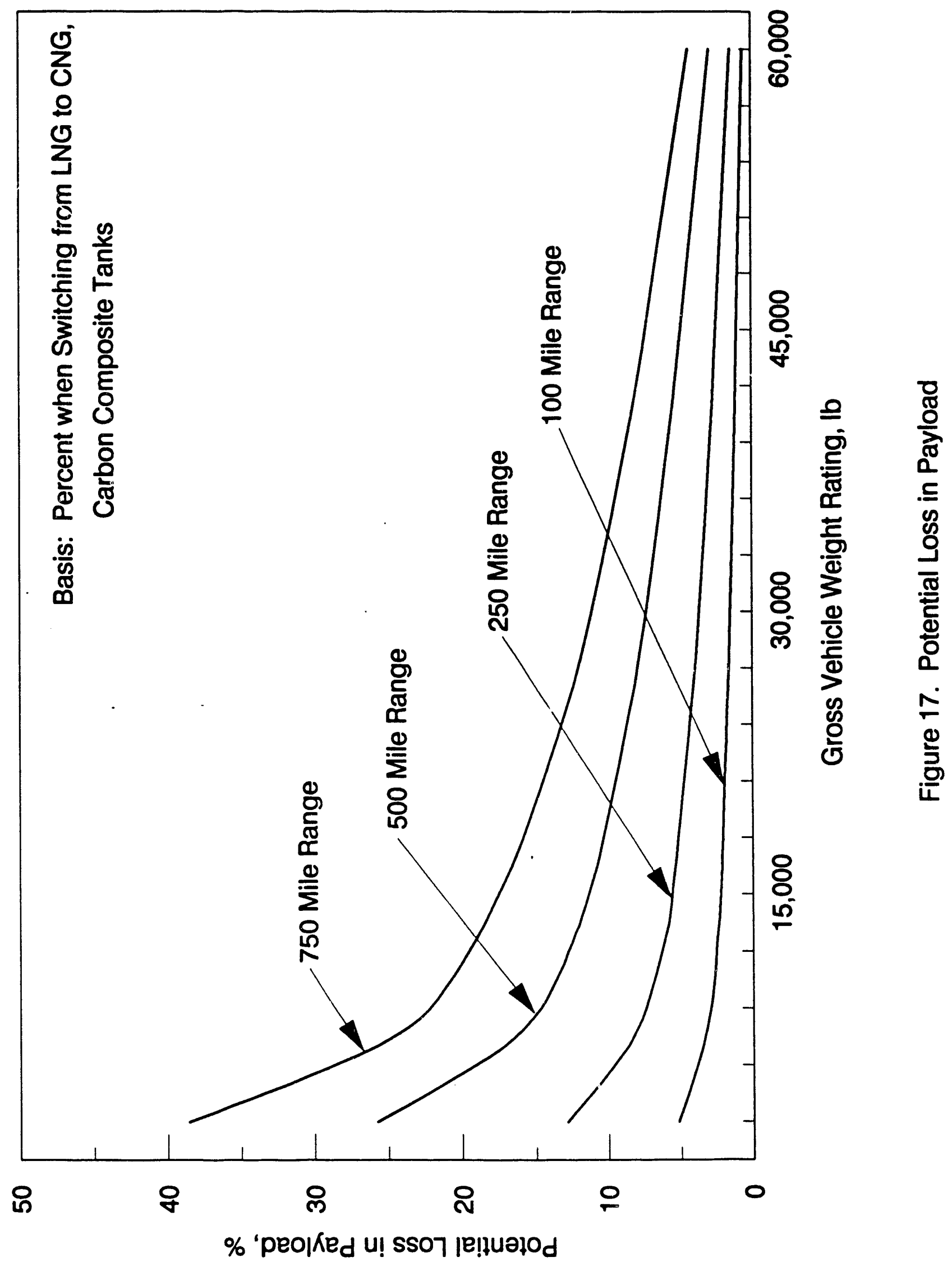




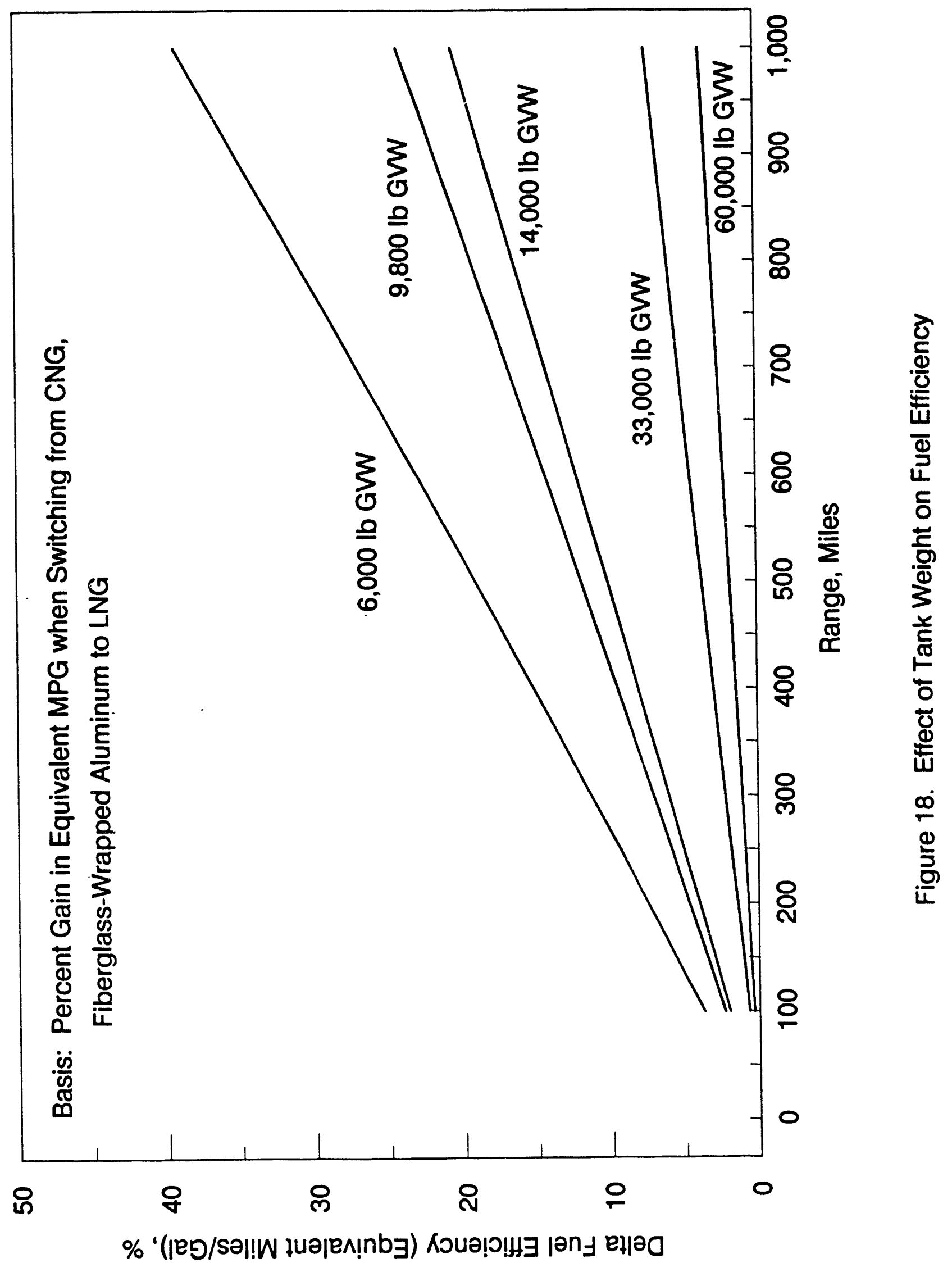




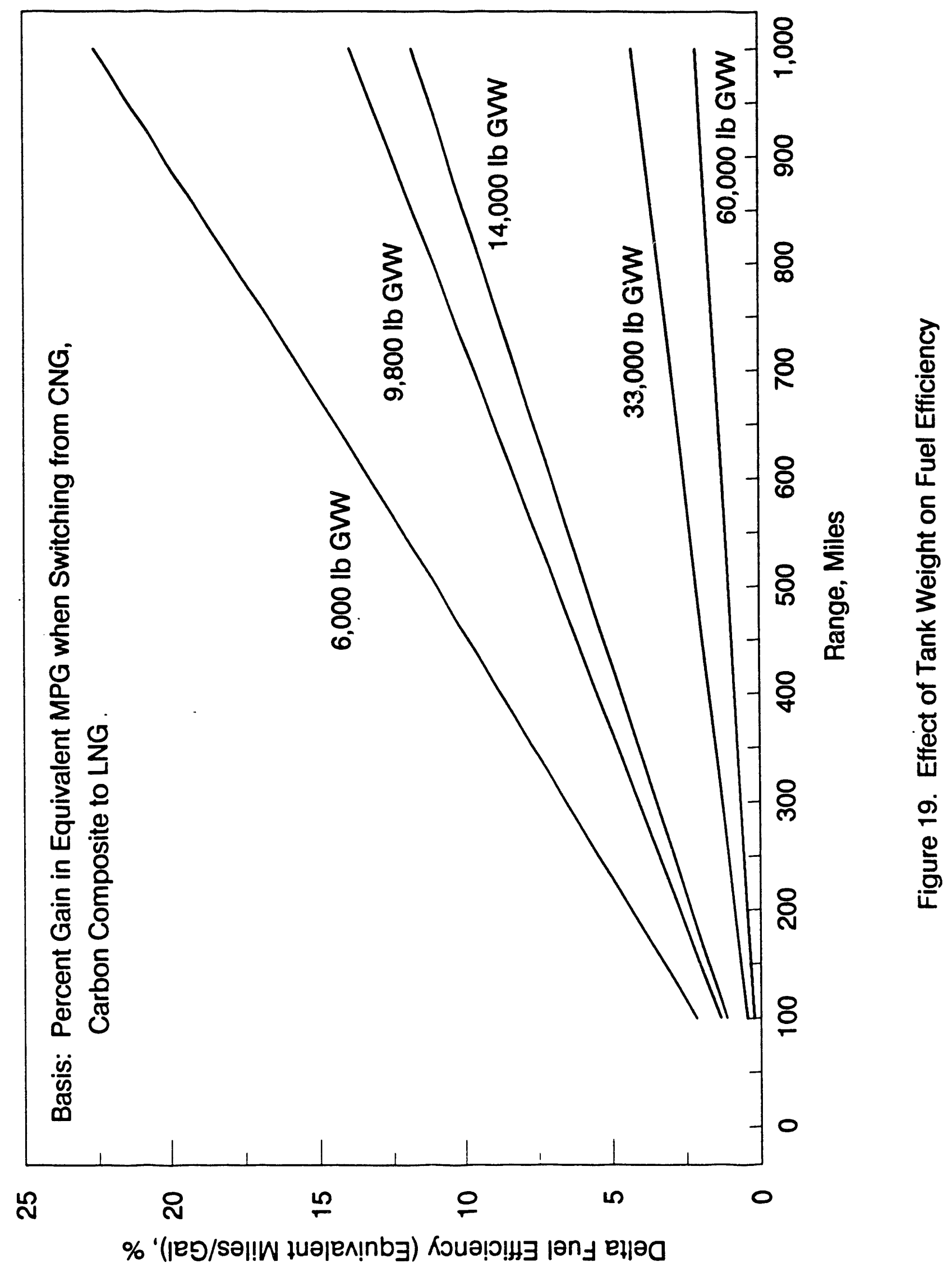


such an analysis be initiated. In the meantime it is reemphasized that the advantages of LNG versus CNG cannot be easily generalized but must be studied in detail for each potential fleet application. Figures 16 through 19 do indicate the desirability of considering LNG in many applications.

\section{HEAVY-DUTY VEHICLES OTHER THAN TRUCKS}

The number of trucks and other heavy-duty vehicles on the road as of 1987 are given in Table 1.

Because trucks are by far the dominant contributor to total vehicle miles traveled, they have been the primary focus of this study. Trucks also cover a wider range of vehicle weights than buses. Thus, any analyses of buses could be fitted within the overall range of parameters covered for trucks.

Average fuel consumption for transit buses is computed at $3.6 \mathrm{miles} / \mathrm{gal}$, for intercity buses it is $6.9 \mathrm{miles} / \mathrm{gal}$, and for school buses it is $9.0 \mathrm{miles} / \mathrm{gal}(6 \mathrm{a})$. Because buses generally travel about the same routes each day, it is possible to predict the range requirement for an individual bus. However, a transit authority or other fleet operator would want a single tank design for all buses of a given size, so that they would be interchangeable on routes. Therefore one must know the maximum variability in daily miles from one route to another. Without having data for this analysis, it was simply assumed that the required range would be equal to twice the average daily mileage. $A$ rough tank weight analysis is then given in Table 2.

The bus data are not as amenable to calculating a fuel efficiency effect and a payload effect, as was done for trucks, so it is harder to derive a quantitative estimate of the benefits of LNG usage. Payload in buses is usually phrased in terms of number of passengers rather than in terms of weight: For instance it has been reported that a CNG bus conversion results in reducing the passenger capacity by 15 passengers $(3,12)$ to 17 passengers $(18)$. It appears that the "average" transit bus would show a worthwhile improvement in fuel efficiency when using LNG instead of CNG. For school buses, however, the improvement is probably not significant and would be offset by boiloff problems created by long periods of standing idle.

Off-road vehicles are also suitable for LNG use. Locomotives are a prime candidate. The use of LNG instead of CNG is reported to decrease the number of fuel tenders on a unit train from nine to two $(6)$. If the unit train is considered to consist of 100 cars, the payload capacity effect is a gain of $7 \%$. 
Table 1.

Population of Heavy-Duty Vehicles and Miles Traveled

$\begin{array}{lrrr}\text { Vehicle Type } & \begin{array}{c}\text { Number of } \\ \text { Vehicles, } \\ \text { Thousand }\end{array} & \begin{array}{c}\text { Average } \\ \text { Annual Miles } \\ \text { Traveled }\end{array} & \begin{array}{c}\text { Total } \\ \text { Vehicle Miles, } \\ \text { Million }\end{array} \\ \begin{array}{l}\text { Trucks, Gasoline } \\ \text { Light }\end{array} & 39,944 & 10,599 & 423 \\ \begin{array}{l}\text { Medium } \\ \text { Light-Heavy }\end{array} & 872 & 8,594 & 7 \\ \text { Heavy-Heavy } & 575 & 6,762 & 4 \\ \text { Trucks, Diesel } & 376 & 8,300 & 3 \\ \quad \text { Light } & & & \\ \text { Medium } & 949 & 11,216 & 11 \\ \text { Light-Heavy } & 151 & 12,985 & 2 \\ \text { Heavy-Heavy } & 185 & 14,668 & 3 \\ \text { Transit Bus } & 1,449 & 47,259 & 68 \\ \text { Intercity Bus } & 60 & 31,100 & 2 \\ \text { School Bus } & 20 & 51,000 & 1 \\ & 499 & 7,400 & 4\end{array}$

Table 2.

Tank Weight Analysis for Buses

Miles Per Gallon

Average Daily Miles

Range Required, Miles
Transit
Bus

Gallons Diesel or Gasoline

Equivalent Gallons LNG

Equivalent Gallons CNG

Tank Weight, LNG, Pounds

Tank Weight, CNG Carbon

Tank Weight, CNG Aluminum

LNG Weight Advantage Versus Carbon

LNG Weight Advantage Versus Aluminum

3.6
99
198
55
104
228
210
820
1,280
610
1,070

Intercity

Bus

School

Bus

6

6.9

163

326

47

89

195

180

700

9.0

41

82

9

14

30

60

220

180

160

520

920

120 


\section{VARIATIONS WITH LOCATION}

In order to discern whether there might be large variations in LNG/CNG attractiveness ratios with location, four wiclely separated cities were chosen (Figure 20):

- Baltimore, Maryland

- Chicago, Illinois

- Houston, Texas

- Los Angeles, California.

Those locational factors presumed to affect the LNG/CNG ratios include:

- Ambient temperatures

- Average daily miles traveled

- Distance from existing LNG facilities.

\section{EFFECT OF TEMPERATURE}

The higher the ambient temperature, the lower the storage capacity of a CNG tank, the shorter the vehicle range, the higher the effective tank weight per unit of energy stored, and the lower the overall efficiency of a CNG vehicle system.

Higher temperatures will also increase the heat absorption by LNG tanks and the rate of liquid boiloff. However, LNG tanks can sit for 2 weeks or more before venting begins, so this should never be a problem for fleet vehicles. Ambient temperature should have no appreciable effect on LNG tankage. It will have some effect on transfer losses when the coupling lines reach higher temperatures between successive vehicle fills, but this should be a minor effect.

To present the complete effect of increasing CNG specific tank weight on system energy efficiency relative to LNG temperature would require a whole family of curves showing the changes with vehicle weight, range, and tank material. For illustrative purposes a 14,000-lb GVW truck with a range of 250 miles and fiberglass-wrapped aluminum CNG tanks was chosen. In Figure 21, the upper curve gives the overall change in energy efficiency because of change in CNG tank capacity between the four cities. The effect is fairly small, with a $0.25 \%$ difference in efficiency between Chicago and Houston. Houston is relatively less attractive for CNG.

Ambient temperatures also affect the amount of energy required to make CNG or LNG, as was seen in Figure 2. The effect is much more important with LNG than CNG, with higher temperatures being unfavorable. Thus, it works in the opposite direction as the CNG tank capacity effect, making hotter cities less attractive for LNG. Again, a whole family of curves would be required to show the complete range of effects as a function of liquefaction plant sizes and efficiencies and plant inlet temperatures and pressures. The importance of individual site-specific analyses is again obvious.

For illustration, a liquefaction plant capacity of $100,000 \mathrm{gal} /$ day and an inlet pressure of 500 psi was chosen. The effect of inlet temperature on energy required for LNG and CNG production was obtained from Figure 2 and the difference divided by the LNG plant energy use obtained from Figure 5. Results are plotted as the lower curve in Figure 21. It indicates a potential energy efficiency disadvantage of $3.5 \%$ for LNG in Houston compared to Chicago. Of course, if the LNG were obtained from a pressure-letdown partial liquefaction type of installation having zero net energy requirement, there would be no difference between any of the cities. Similarly, if the LNG were obtained from an import terminal, there would be no ambient temperature effect. 


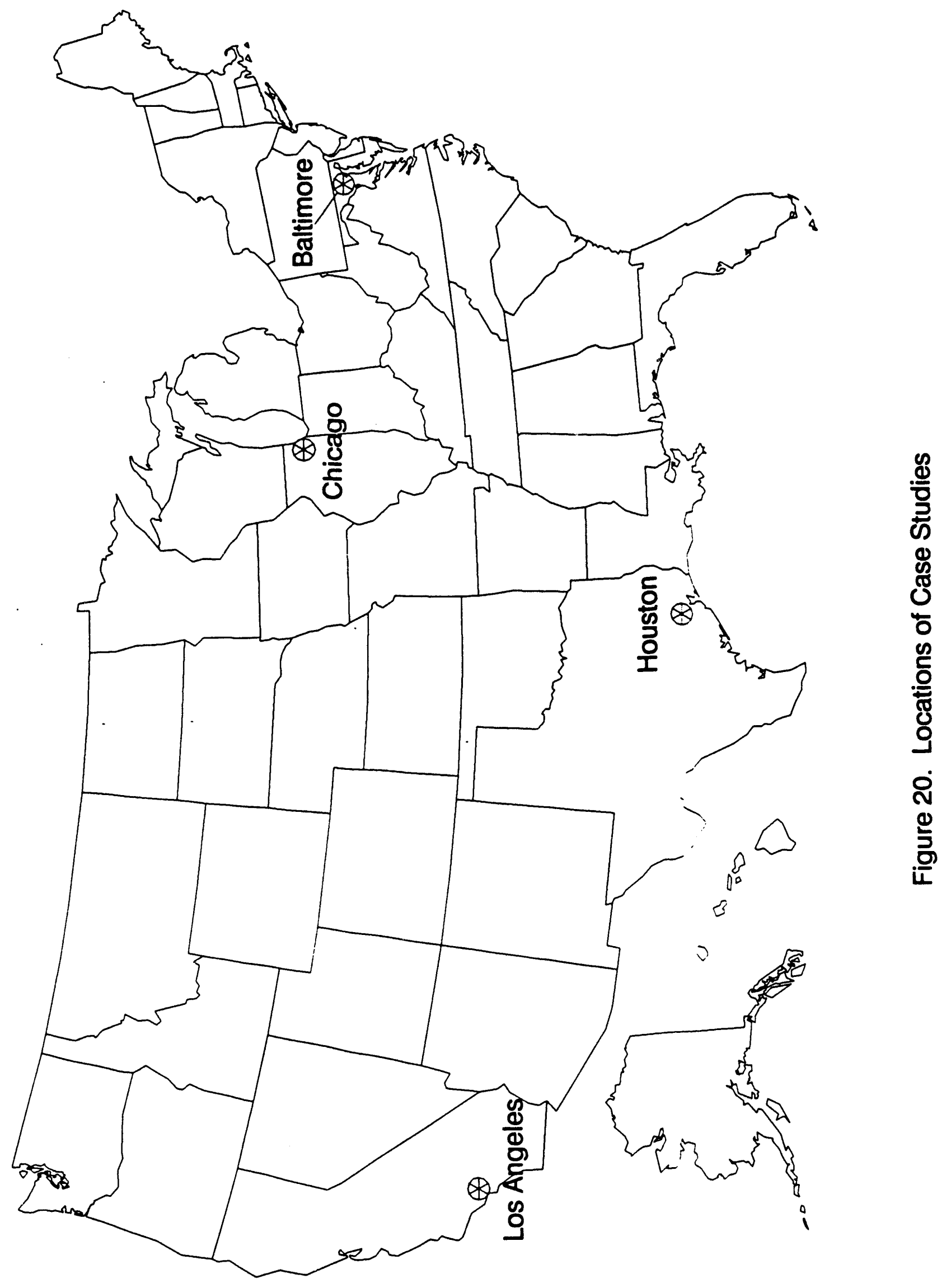




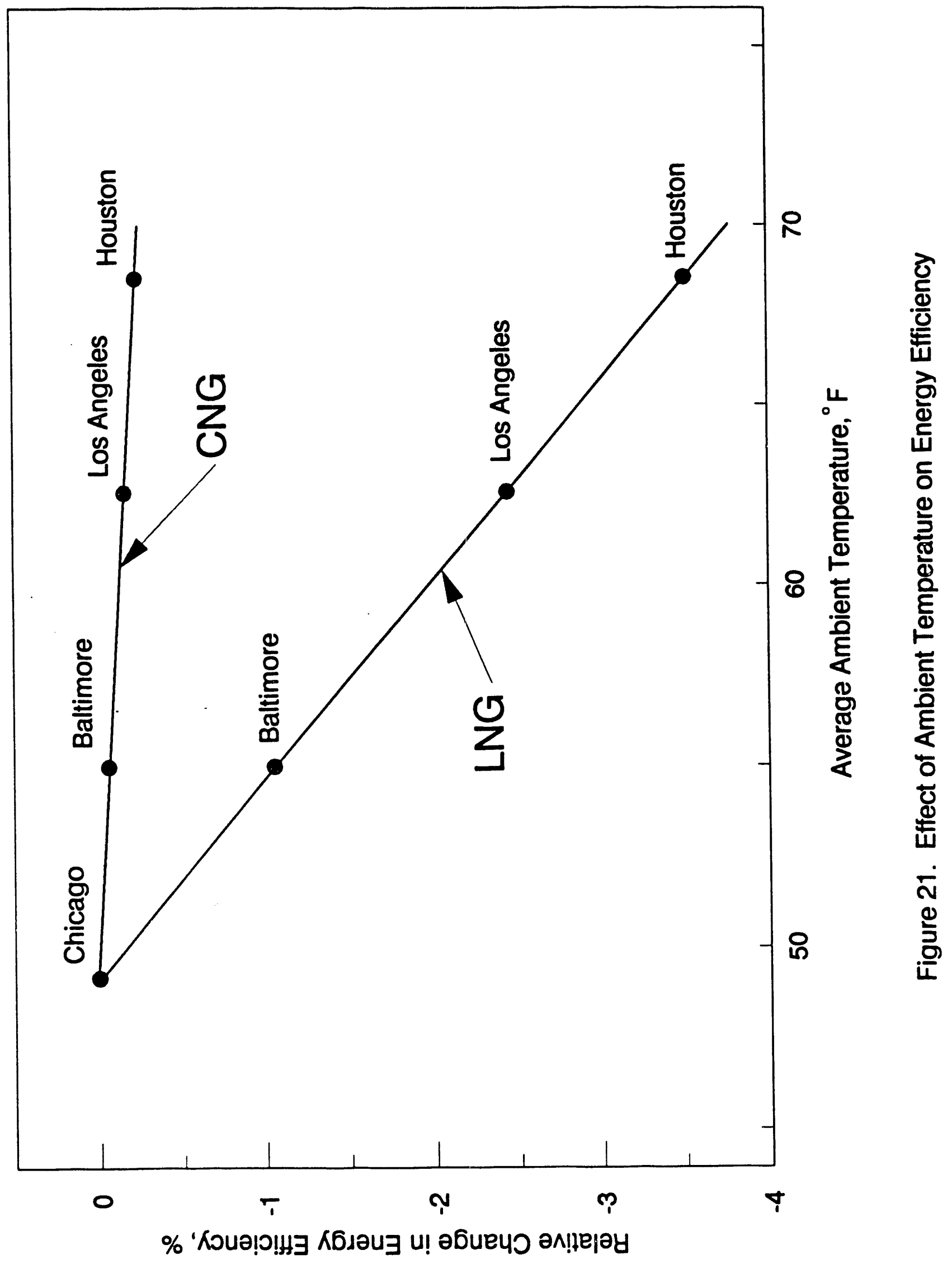


These results do reinforce the advantages that could accrue from improving the energy efficiency of small- and medium-scale liquefaction plants.

\section{EFFECT OF MILES TRAVELED}

Previous sections have shown how required vehicle range affects the relative efficiency of LNG and CNG systems. Vehicle fleet needs will vary from city to city, although a single company operating in many cities would likely prefer to maintain uniform vehicle specifications. Thus a city to city comparison based on changing vehicle characteristics probably is not valid. It may, however, help choose the best starting points for site-specific analyses.

As a surrogate parameter for required vehicle range, census data for population density per square mile were used. It was assumed that each person in each city required the same number of trips by commercial fleet vehicles, and that the distance traveled on each trip would be inversely proportional to the square root of the population density.

Results, plotted in Figure 22, show that in Houston LNG would have a $2.5 \%$ greater efficiency advantage over CNG than in Chicago. By coincidence, the city rankings appear in the same order in Figure 22 as in Figure 21 and the maximum difference between the cities is of the same order of magnitude. Thus for the cities selected, Figures 21 and 22 approximately cancel out, leaving no significant differences between cities. Clearly this result was a happenstance. For any two cities selected at random, the conclusion to be drawn from Figures 21 and 22 is that a calculation of system efficiency of LNG versus CNG could differ by several percent because of climatic and demographic factors.

\section{DISTANCE FROM LIQUEFACTION PLANT}

A comparison of Figures 7 and 20 suggests that fleets in Baltimore are likely to be within practical trucking distance from an existing peak-shaving liquefaction plant, fleets in Chicago may be, and those in Houston and Los Angeles will not be. For the first LNG fleets inis could be an important consideration, but if LNG is to be adopted on a large scale, new facilities will eventually be needed in any case. New liquefaction plants can then be sited at optimum locations, which could be at a fleet refueling site in some cases and at an optimum spot on the pipeline in other cases. When new facilities are required, there does not seem to be a large geographic advantage for one city over another, other than differences in the cost of gas. 


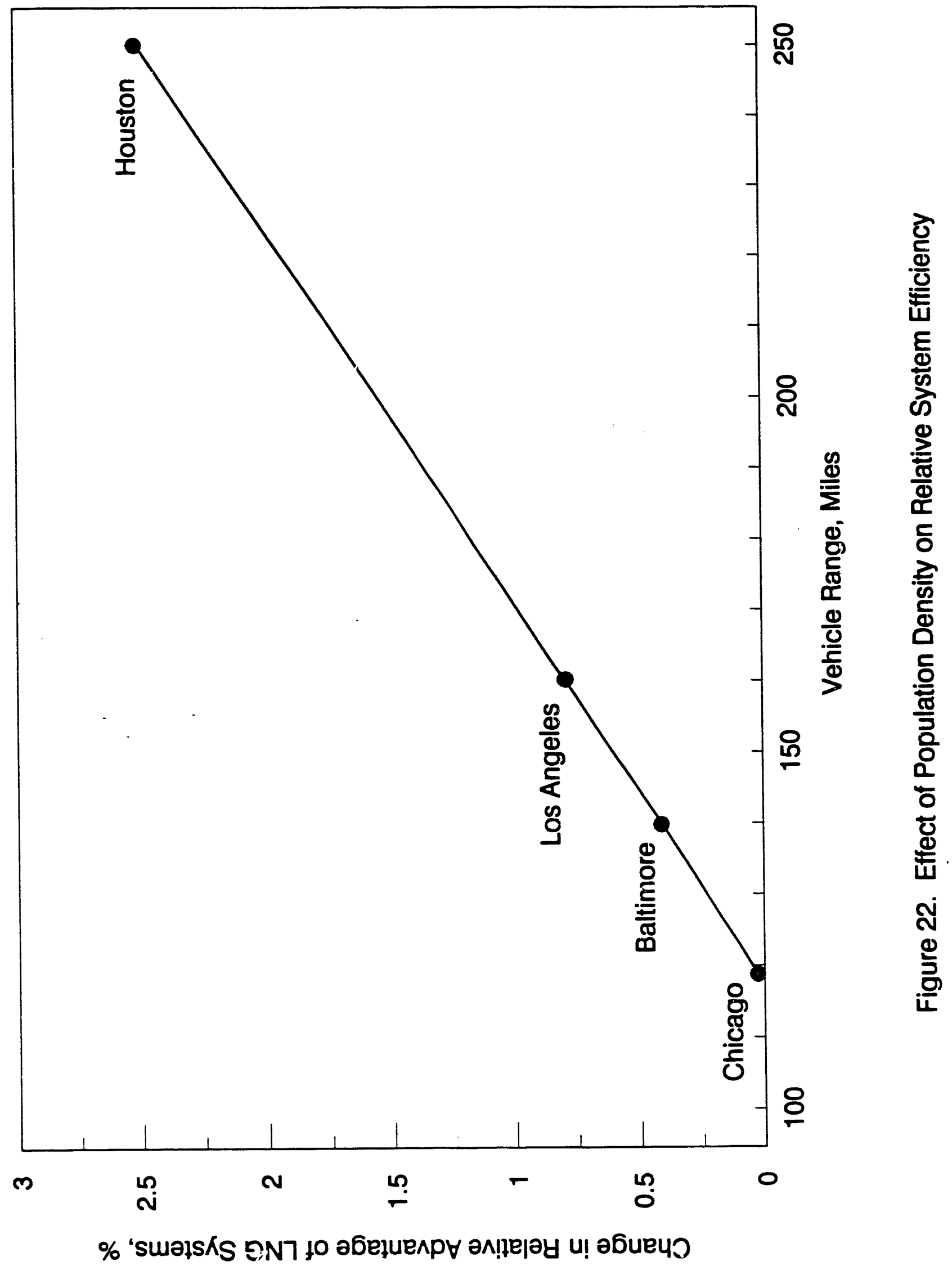




\section{COMPARISON OF INFRASTRUCTURE COSTS}

A number of studies have addressed the question of infrastructure costs, particularly comparing CNG to other alternative fuels $(2,3,5,7,8,10,14,16,20,21,23,25)$. Therefore, no attempt was made in this report to do a detailed economic analysis of either CNG or LNG systems. It has been shown in this study that a comparative analysis is certain to be highly site-specific, depending on the source of the LNG. Some broad observations, however, can be made.

One major component of an infrastructure system for vehicular use of natural gas--the natural gas pipeline system--is already in place, regardless of whether CNG or LNG is used. For a second major component, it is generally assumed that existing service stations and fleet service yards can be used and simply modified for natural gas use. In many or most cases, a larger pipeline, which may be 16 in. or more in diameter ${ }^{(10)}$ must be laid from the nearest distribution main. If efficient small liquefiers were available, the only infrastructure difference between LNG and CNG would be the differ nce between a compressor with storage cascade and a liquefier with a storage tank. The liquefier would be more expensive than the compressor but the CNG storage would be more expensive than the LNG storage (in cases where CNG storage is used).

Because of the lack of efficient small liquefiers, an LNG infrastructure is likely to eventually evolve somewhat differently, as shown in Figure 6. The energy cost of shipping LNG 150 miles would be about $250 \mathrm{Btu} / \mathrm{lb}$. The difference in liquefaction energy required by a 10,000 gallon per day liquefier at a retail outlet and a $100,000 \mathrm{gal} /$ day liquefier at a regional distribution point is estimated to be about $750 \mathrm{Btu} / \mathrm{lb}$ (Figure 5). Thus, unless considerable improvements are made in small-scale liquefier technology, the optimum solution will tend toward larger regional LNG production plants serving a number of fleet locations, and perhaps with intermediate bulk storage sites as shown in Figure 6.

Large fleets may opt for an on-site liquefier. Averaging several results from the literature $(2,3,16,21)$, it appears that an LNG liquefaction facility with a capacity in the range of 10,000 to $40,000 \mathrm{gal} /$ day can be purchased for $\$ 100$ to $\$ 200 / \mathrm{gal} /$ day of capacity. By comparison, the average of several studies on large CNG compressors yields a capital cost of about $\$ 60$ for an equivalent fuel capacity. Without question, liquefaction will cost more than compression at the same inlet conditions. However, there may be other counterbalancing economic factors. Large LNG facilities located on pipelines may be able to negotiate more favorable gas purchase prices. Different financing arrangements may be available for stand-alone facilities than for retail facility modifications. Houston Metro calculates the fuel cost of LNG and CNG to be equal (19a). Therefore the higher infrastructure cost for LNG does not appear to be a serious deterrent, although lower-cost liquefiers would obviously be advantageous. 


\section{COMPARISON OF GREENHOUSE GAS EMISSIONS}

The two most important greenhouse gases are carbon dioxide $\left(\mathrm{CO}_{2}\right)$ and methane. There are various ways in which the amount of carbon dioxide and methane emitted per ton-mile or passenger-mile will be affected by whether CNG or LNG is used. The most extensive analysis comparing CNG and LNG is that of DeLuchi $(7,8)$. He concludes that for heavy-duty vehicles (using a 100-year time horizon to calculate methane effects) switching from reformulated diesel fuel to $\mathrm{CNG}$ would cause a $6.2 \%$ increase in $\mathrm{CO}_{2}$-equivalent greenhouse gas emissions, whereas switching to LNG would cause a $7.6 \%$ increase. Most of the difference is due to the greater energy required for liquefaction versis compression and to an assumption of higher methane leakage rates for LNG systems.

\section{METHANE EMISSIONS}

Methane is a powerful greenhouse gas, being equivalent to 10 to 60 times its weight of $\mathrm{CO}_{2}$, depending on the time horizon considered. Therefore, even relatively small amounts of methane emitted can be significant.

It is assumed that tailpipe emissions of unburned methane will be the same per pound of fuel burned, whether as LNG or CNG. The other sources for methane emissions are leaks, spills, and venting from tanks. DeLuchi $(7,8)$ assumes methane leakage rates from LNG systems are $17 \%$ higher than from CNG systems in light-duty vehicles and $20 \%$ higher for heavy-duty vehicles. It is hard to find justification for differences of this magnitude. CNG systems are held at much higher pressures and involve more fittings capable of leaking.

Both CNG and LNG systems suffer from some "spillage" during refueling. Connecting and disconnecting a refilling probe to the vehicle fuel tank inevitably results in trapping a small amount of material in the space between the two shutoff devices. The density of LNG is more than twice that of CNG, so that more material can be trapped in the same space and subsequently released to the atmosphere when the refueling connection is broken.

When LNG tanks stand idle for an extended period, pressure will build up until it exceeds the tank relief pressure and "boiloff" losses will then begin venting to the atmosphere. This is a potential source of methane emissions not present in CNG systems, but no way of quantitatively estimating such emissions could be found. It is possible that higher leakage rates from CNG systems could compensate for boiloff losses from LNG systems.

\section{EFFECT OF ENGINE EFFICIENCY}

Carbon dioxide emissions are directly proportional to the amount of fuel consumed, which is proportional to engine efficiency. Potential improvements to engine efficiency achieved by taking advantage of the cryogenic properties of LNG were illustrated in Figure 9. An engine efficiency increase of $2 \%$ to $3 \%$ should result in a corresponding $2 \%$ to $3 \%$ decrease in greenhouse emissions for LNG.

\section{EFFECT OF FUEL TRANSPORTATION}

In cases where LNG is trucked from an off-site liquefaction plant to the fleet refueling site, the fuel used in this transfer operation would result in $\mathrm{CO}_{2}$ emissions not present in a CNG system. The maximum distance for trucking is assumed to be about 150 miles, which would result in additional fuel consumption equivalent to about $1 \%$ of the fuel transported. For an on-site liquefier, of course, there would be no transportation energy requirement. 


\section{EFFECT OF COMPRESSION OR LIQUEFACTION}

There are two ways in which compression or liquefaction will differ with respect to greenhouse influence. One is the amount of energy used. The energy required for liquefaction can vary from zero (pressure let-down liquefier in special situations) to $30 \%$ of the LNG produced (one-vehicle home liquefier). Compression energy varies over a much smaller range, from about $2 \%$ to $5 \%$ of the CNG produced.

The second way in which greenhouse effects will vary depends on the energy source used for compression or liquefaction. Compression is usually accomplished with electric motors and the net greenhouse effect depends on whether the electricity comes from nuclear-powered plants, coalfired plants, gas-fired plants, hydroelectric facilities, or other sources. Liquefaction energy requirements could also come from electricity, but are more commonly derived from gas fired engines or turbines. DeLuchi has calculated (using a typical United States mix of electrical power sources) that the net $\mathrm{CO}_{2}$-equivalent emissions from liquefaction are only slightly higher than from compression if natural gas and electricity are the respective energy sources $(7,8)$. That is a correct approach if one considers what is likely to happen based on current circumstances. On the other hand, if policy options are being considered, and there is a national commitment to use more natural gas, the energy of CNG compression could be provided entirely from natural gas as well. Therefore the only comparison made here is on the basis of relative energy used.

Focusing only on an optimally located medium-size LNG facility, estimated energy consumption is equal to $16 \%$ of the LNG produced. Non-optimum factors could push this above $20 \%$. With compression requiring as little as $2 \%$ of the throughput, energy requirements and therefore $\mathrm{CO}_{2}$ emissions could be as much as $\mathbf{1 8 \%}$ higher for liquefaction.

For an ideal liquefaction case, consider that the liquefier would be located at a pressure letdown point from 750 to 100 psi. Expansion to atmospheric pressure would yield $15 \%$ liquid. Pumping the remaining $85 \%$ back up to 100 psi for reinjection into the system would require $2.8 \%$ of the throughput. Thus, a range of $2.8 \%$ to $18 \%$ higher energy use for liquefaction is possible.

A reasonable goal for future technology improvement might be to reduce the liquefaction energy requirement in the general case down to the level of $10 \%$ currently achieved in very large LNG plants. Then the LNG disadvantage with respect to CNG would be about $8 \%$ of throughput.

\section{EFFECT OF TANK WEIGHT ON MILEAGE}

CNG tanks weigh more than LNG tanks, reducing the miles per gallon achieved by a vehicle. Greenhouse emissions are directly proportional to miles per gallon. As was seen in Figure 18, a 14,000 -lb GVW truck with a 250 -mile range, for example, would suffer a loss of $5 \%$ in miles per gallon in switching from LNG to CNG. Thus, greenhouse emissions in the form of $\mathrm{CO}_{2}$ per mile would be $5 \%$ higher for CNG because of tank weight differences.

\section{EFFECT OF TANK WEIGHT ON PAYLOAD LOSS}

If a vehicle's operating characteristics are such that an increase in tank weight forces a compensating decrease in payload, the greenhouse effect works the same as for a decrease in mileage. A percentage decrease in payload means that more vehicles or more trips will have to be used to transport the same amount of goods, and greenhouse emissions $\left(\mathrm{CO}_{2}\right)$ will go up in proportion. As was seen in Figure 16, a 14,000-1b GVW truck with a 250-mile range, for example, could suffer a potential loss in payload capacity of $10 \%$ in switching from LNG to CNG. Thus, greenhouse emissions per ton-mile would be $10 \%$ higher for CNG. 


\section{EFFECT OF MANUFACTURING ENERGY}

An often-overlooked effect in greenhouse analyses is the effect of energy required to manufacture equipment. For instance, this analysis could have been extended to cover the energy required to manufacture compressors versus liquefaction plants. Only a first-order calculation was made, limited to the energy required to manufacture CNG tanks versus LNG tanks.

The energy required to manufacture automobiles and vans is found to be about $28,000 \mathrm{Btu} / \mathrm{lb}$, curb weight ${ }^{(6 a)}$. It was simply assumed that the same ratio applied to manufacturing either LNG or CNG tanks. The difference in energy cost between CNG and LNG tanks was then calculated as a percent of fuel used. The results are independent of vehicle size and depend only on required range (Figure 23).

\section{COMPOSITE EFFECTS}

It will have become obvious by now that there must be a large range of uncertainty in any ranking of LNG against CNG. Results are highly dependent on the liquefaction technology used and on whether or not payload capacity is affected by CNG tank weight.

In order to provide a visual feeling for the relative magnitude of the different parameters affecting greenhouse emissions, several composite charts are presented in Figures 24 through 28 . In these charts a bar above the zero line indicates the percent by which LNG greenhouse emissions would exceed CNG emissions, and vice versa for a bar extending belcw the zero line. A solid bar represents either an unvarying estimate or else the lower limit of an estimate with a range. An unshaded bar represents the upper limit of an estimate with a range.

Adding the bars on each figure gives the results shown in Table 3. In all cases, one end of the range shows an appreciable superiority for LNG while the other end of the range shows an appreciable superiority for CNG. The higher the required vehicle range, the more favorable the result for LNG. If loss-of-payload effects are assumed to occur, the overall balance would be clearly in favor of LNG.

Table 3.

Relative Greenhouse Effects

\begin{tabular}{|c|c|c|c|c|}
\hline CNG Tanks & $\begin{array}{l}\text { Range } \\
\text { Miles }\end{array}$ & $\begin{array}{l}\text { GVW } \\
\text { Pounds }\end{array}$ & $\begin{array}{l}\text { Percent by which } \\
\text { CNG Emissions } \\
\text { Exceed LNG at } \\
\text { Upper End of Range }\end{array}$ & $\begin{array}{l}\text { Percent by which } \\
\text { LNG Emissions } \\
\text { Exceed CNG at } \\
\text { Lower End of Range }\end{array}$ \\
\hline $\begin{array}{l}\text { Aluminum } \\
\text { Aluminum } \\
\text { Aluminum } \\
\text { Aluminum } \\
\text { Carbon }\end{array}$ & $\begin{array}{l}100 \\
100 \\
500 \\
500 \\
500\end{array}$ & $\begin{array}{r}9,800 \\
33,000 \\
9,800 \\
33,000 \\
33,000\end{array}$ & $\begin{array}{r}7.3 \\
3.4 \\
37.6 \\
15.9 \\
9.4\end{array}$ & $\begin{array}{r}14.6 \\
16.0 \\
4.8 \\
12.8 \\
14.5\end{array}$ \\
\hline
\end{tabular}




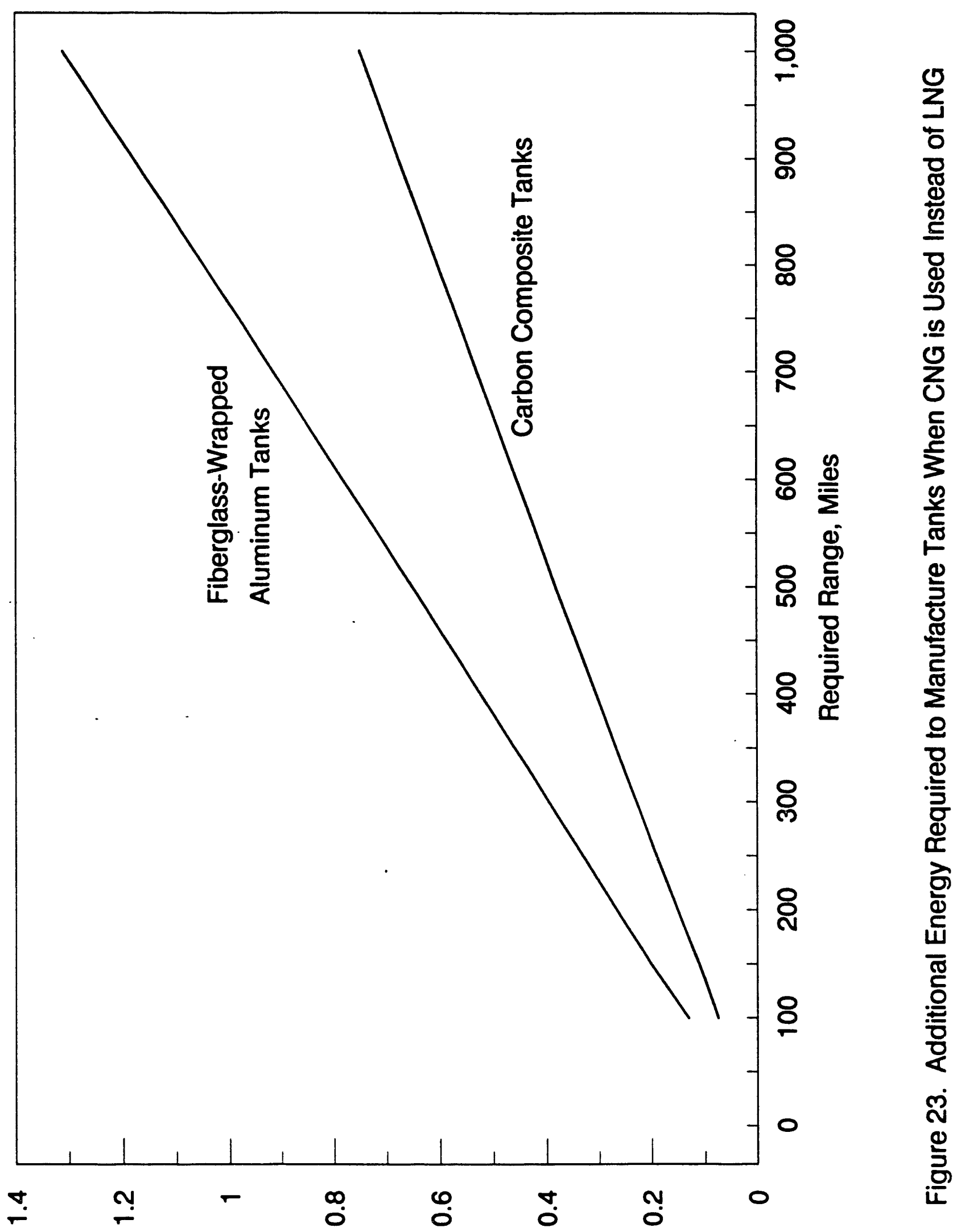

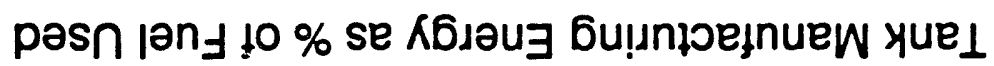




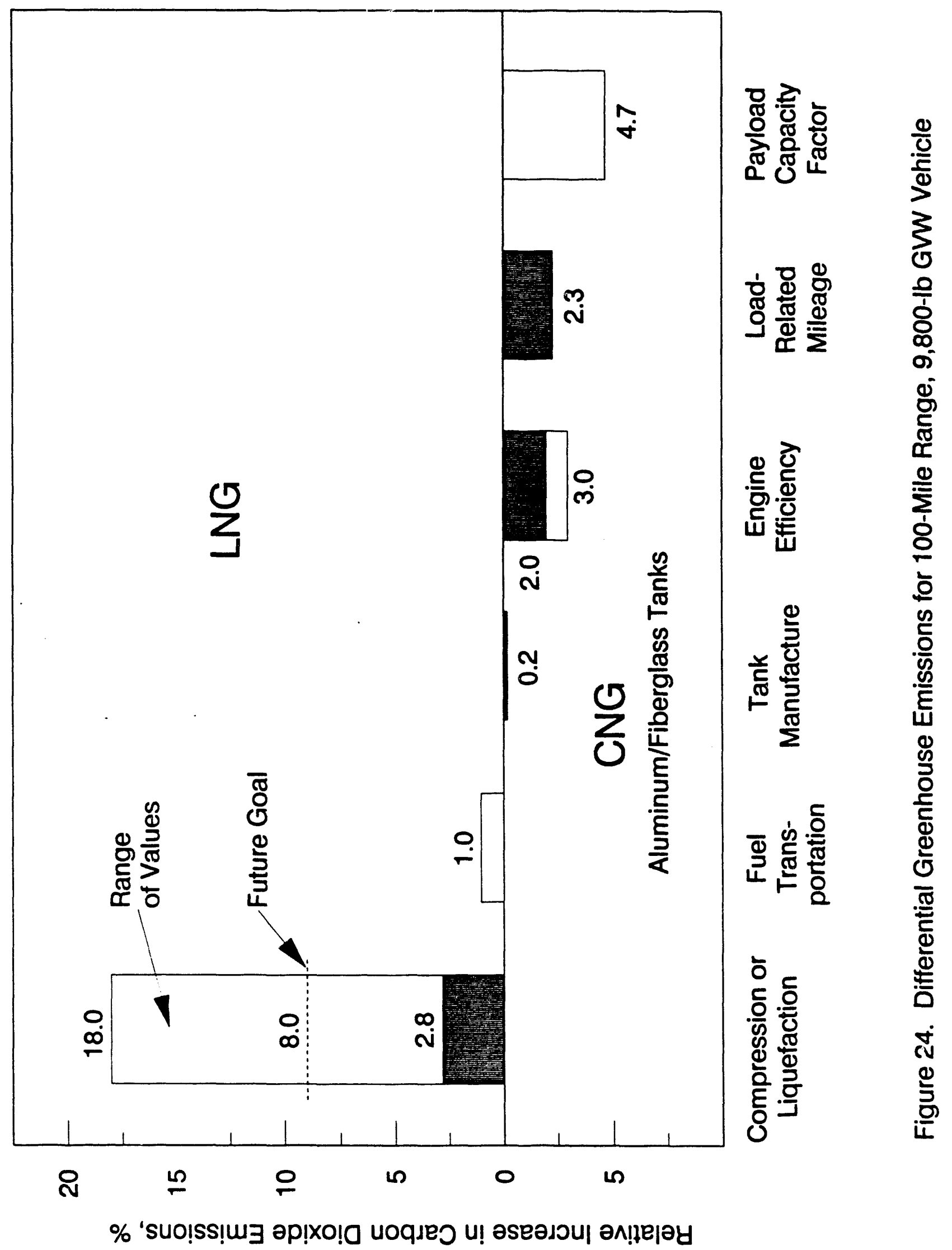




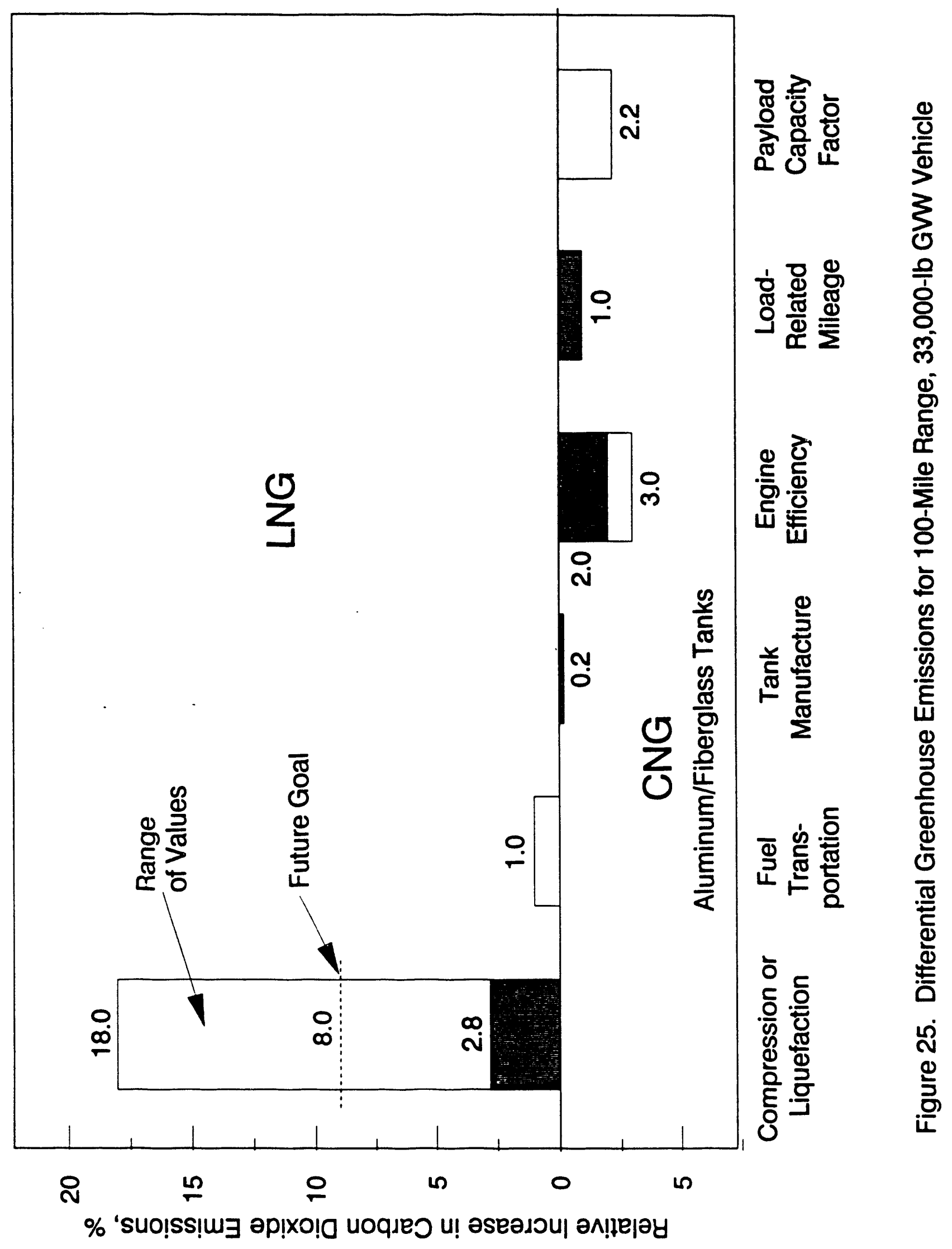




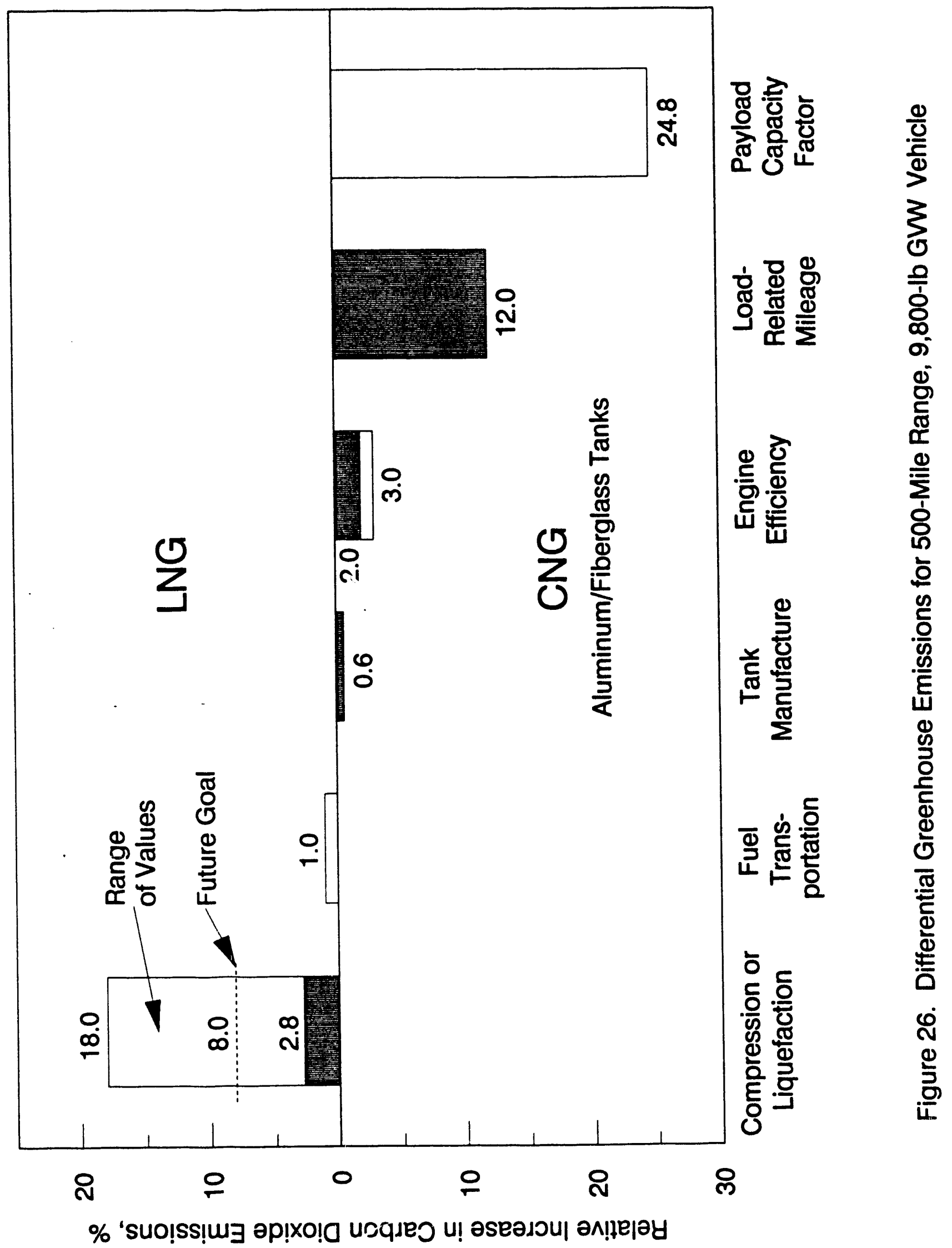




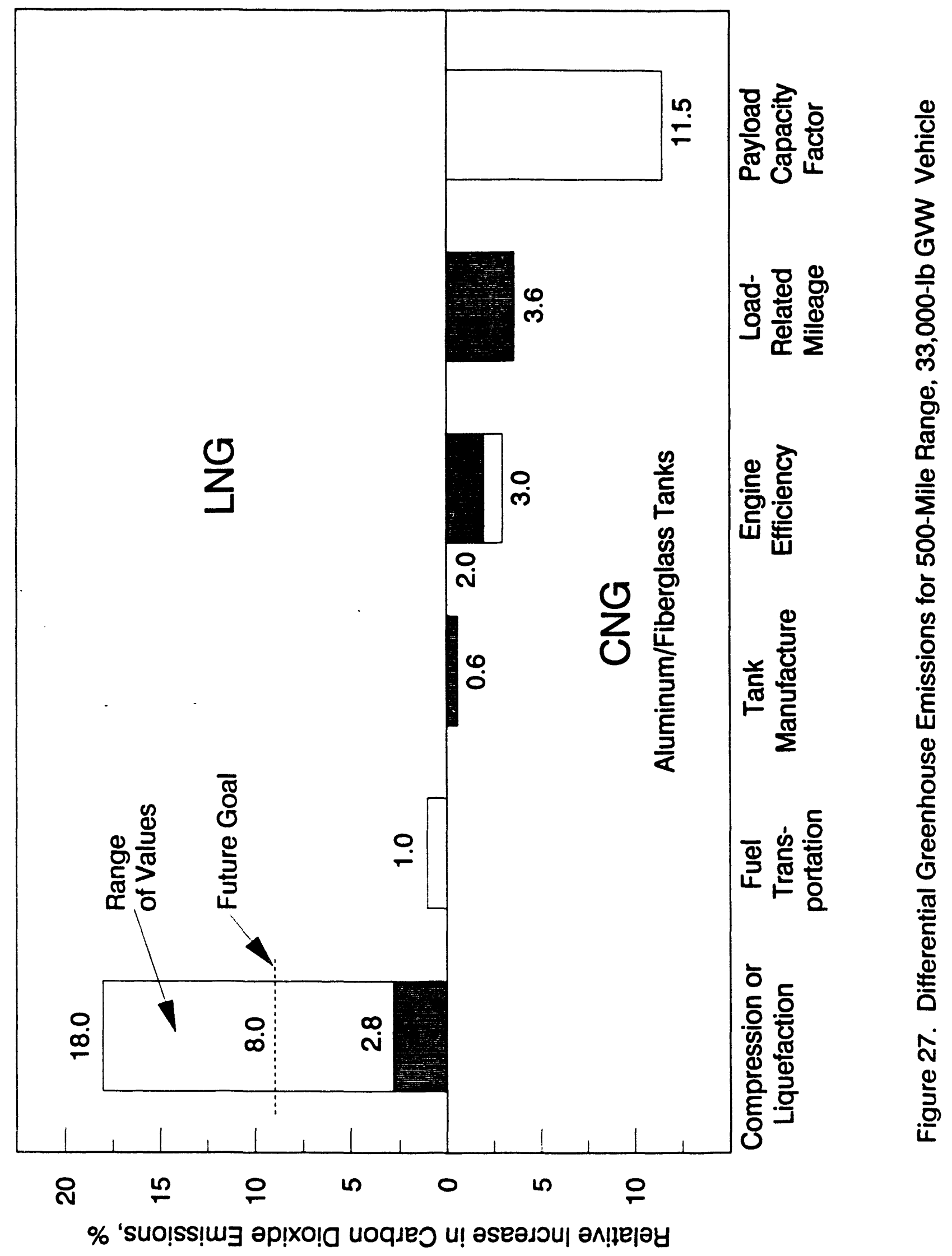




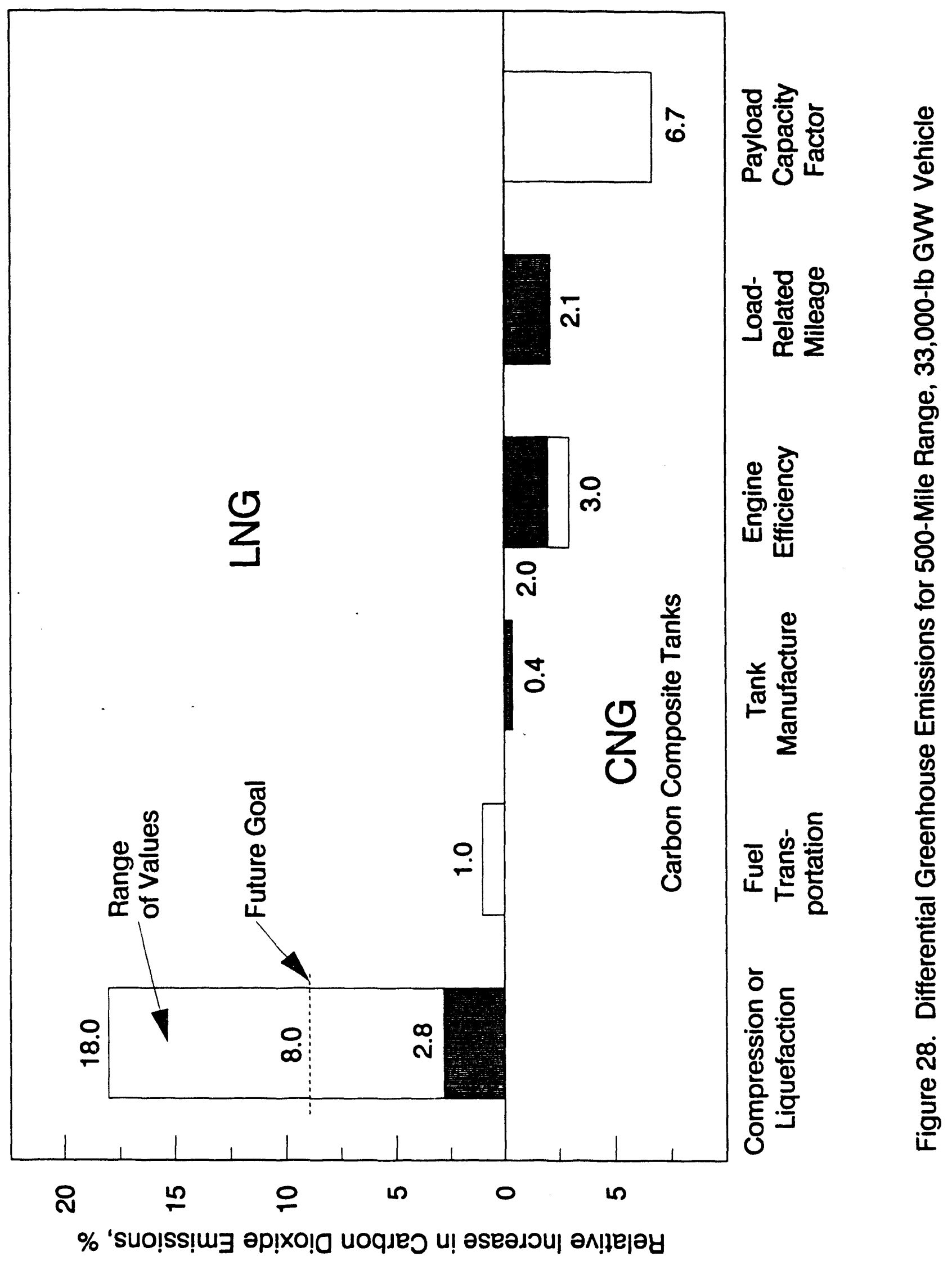




\section{SAFETY CONSIDERATIONS}

The safety concerns for LNG and CNG are similar in most respects. The major hazard results from leakage into confined spaces, such as garages, and the buildup of an explosive atmosphere therein. Assuming that both LNG and CNG vehicles are designed for the same range, both would carry approximately the same mass of fuel so that total emptying of the fuel tanks would have the same effect. However, there would appear to be a greater likelihood of leaks from CNG tanks than from LNG tanks. The CNG tanks are under much higher pressure and would require more extensive piping and more fittings at which leaks could develop. A large leak developing in a CNG system would result in rapid loss of the entire contents. A similar leak in the vapor space of an LNG tank would, after the vapor were vented, only continue to lose material at the liquid boiloff rate of a few percent per day.

Both CNG tanks and LNG tanks are structurally quite strong and unlikely to fail, although CNG failures have been recorded (23). In a massive failure LNG could create a more hazardous situation because of the low-temperature vapors created. CNG, being lighter than air, will disperse rapidly from a massive tank failure. A massive LNG spill would result in liquid pools that would quickly boil away, but the cold methane vapor created would be about twice as dense as air and could collect in low spots for a short period of time. Gaseous methane issuing from a leak in a high-pressure CNG system will be cooled because of the J-T effect discussed earlier. However, the maximum cooling that could occur is on the order of $100^{\circ} \mathrm{C}$, and methane would still be lighter than air at that temperature.

Both LNG and CNG tanks should be resistant to fire. The double-walled LNG tank should be more so. It has been reported that dousing with liquid methane will quench a fire ${ }^{(13)}$ because of its low temperature, heat sink effect, and high ignition temperature. Spraying an LNG puddle with water would greatly increase the rate of vapor generation and raise the hazard level rather than lower it.

There are three specific ways in which LNG may be considered to be more hazardous than CNG:

- Because the odorants used in natural gas are not volatile at LNG temperatures, leakage from the vapor space will have no warning odor.

- When vehicles are left idle for extended periods, LNG will eventually exceed the tank relief pressure and start venting into the atmosphere.

- With cryogenic fluids there is a possibility of low-temperature burns caused by accidental contact with the fluid.

With properly designed fill systems the last hazard above should be negligible. It has been reported that poorly designed fueling systems resulted in a requirement that operators wore face masks and gloves during refueling $(8)$.

An extensive safety assessment by Battelle found no significant differences in level of hazard between CNG and LNG systems ${ }^{(22)}$, with CNG having a slight advantage. Nothing in this review contradicts that conclusion. 


\section{CONCLUSIONS}

If the economics of LNG vehicles are generally unfavorable with respect to CNG vehicles, no significant development of LNG will occur. That decision will be made by individual fleet operators based on their own detailed assessments. This study was designed to explore whether or not certain technological or institutional constraints are inhibiting or should be inhibiting operators from choosing LNG systems.

With respect to efficiency of production, it was found that the energy required and the cost of producing LNG are extremely variable, depending on the pipeline supply pressure and the size of the liquefaction system. Methane liquefaction is a still-maturing technology that is not yet approaching theoretical efficiency limits for small- and medium-size systems. Additional research and development in this area could be useful. The energy required for liquefaction ranges from only slightly more than that required for compression, up to an additional $20 \%$ of the energy value of the LNG produced.

The relative economics of producing LNG versus CNG will show about the same range of values as energy usage. There are situations where LNG will cost little, if any, more than comparable quantities of CNG loaded into the vehicle. There are also situations where LNG would be considerably more expensive, but probably none where it would be much less expensive.

In comparing the efficiency of utilization of CNG and LNG in vehicles, the cryogenic nature of LNG provides several potential advantages. Charge-air cooling with LNG could increase engine efficiency by $2 \%$ or $3 \%$. However, new technical developments will be required before this potential advantage can be realized.

The use of LNG refrigeration for cargo cooling is a non-engine related way to recover some of the energy expended in liquefaction. This is unlikely to become a widely used procedure, but could provide appreciable benefits in special niches.

The clearest distinction between end-use efficiencies of LNG and CNG systems is the difference in fuel tank weight. For heavy-duty vehicles, increased fuel tank weight directly reduces transportation efficiency (ton-miles per Btu). Even with the lightest weight CNG tanks envisioned for the future (carbon composite) there is a weight and volume advantage for LNG tanks in heavy-duty vehicles. This study shows that the advantage depends heavily on the truck size and the required travel range between refuelings.

In addition to the direct and definite effect of tank weight on fuel consumption, there is a possible further effect of reduced payload capacity. If the vehicle operating characteristics are such that the added weight and volume of CNG tanks reduces the payload at times, this can cause a greater drop in transportation efficiency than the tank weight effect on mileage. The results of this analysis emphasize the fact that every CNG/LNG comparison will yield different results depending on the specific fleet characteristics involved.

The CNG/LNG comparison will also vary with geographic and demographic factors such as average ambient temperature and urban density.

With respect to total carbon dioxide emissions per ton-mile, it was found that results could range all the way from a significant (15\% or more) advantage for LNG to a similar advantage for CNG. The two most important variables are the energy used for LNG production and the lower transportation energy efficiency resulting from CNG tank weight.

Safety considerations are not significantly different between the two fuels, although CNG may have a slight edge. 
The clear conclusion to be drawn from this brief study is that there is no overall general advantage for either LNG or CNG in the areas of energy efficiency, economics, or environmental effect. Rather, there are some applications in which one will have the advantage and some in which the other will be preferred. Both should be encouraged. Because LNG technology lags that of CNG, additional LNG research and development should be promoted in order to allow fleet operators a choice that provides the maximum benefits achievable with either technology. 


\section{REFERENCES}

1. Acker, George Jr., C.E. Brett, S. Bell, K.C. Midkiff and Y.K. Song (n.d.). "Experience Using LNG as a Marine Engine Fuel," MTS Journal, Volume 23, No. 2, pp. 33-39.

2. Adkins, Roy E. (1989). "An Alternative Transportation Fuel: The LNG Option," American Gas Association conference presentation, Washington, D.C.

3. Biederman, Richard and C. Blazek (1990-1991). "Evaluation and Economic Analysis of LNG for Heavy-Duty Transportation Applications," The LNG Observer, Volume 1, No. 4, Winter, pp. 18-23.

4. Brett, C. Everett, S.R. Bell, K.C. Midkiff and Y. Song (1989). "Experience Operating Medium Size 50-400 HP Diesels on Dual-Fuel," presented at 1989 International Gas Research Conference, Tokyo, Japan.

5. Constable, G.A., C.J. Gibson and A. Gram (1989). "Use of LNG in Heavy-Duty Vehicles," SAE Technical Paper 891670, Society of Automotive Engineers, Warrendale, Pennsylvania.

6. Davis, Robert N. (1991). "Refrigerated Liquid Methane: A New Fuel for Railroads," presented at Distribution/Transmission Conference, American Gas Association, Nashville, Tennessee, April 28-May 1.

6a. Davis, Stacy C. and P.S. Hu (1991). Transportation Energy Data Book: Edition 11, Oak Ridge National Laboratory, January.

7. DeLuchi, Mark A. (1991). "Emissions of Greenhouse Gases From the Use of Transportation Fuels and Electricity," Institute of Transportation Studies, University of CaliforniaDavis and Center for Energy and Environmental Studies, Princeton University.

8. DeLuchi, Mark A., R.A. Johnston and D. Sperling (1988). "Methanol vs. Natural Gas Vehicles: A Comparison of Resource Supply, Performance, Emissions, Fuel Storage, Safety, Costs, and Transitions." SAE Technical Paper 881656, Society of Automotive Engineers, Warrendale, Pennsylva.ria.

9. Ellison, Woody, E.E. Atkins, G. Wai'er and S.G. Zylstra (n.d.). "A Gas-Fired DuplexStirling Cryorefrigerator 'o Liquefy Naiiral Gas for Automotive Fuel," General Pneumatics Western Res/zarch Center, Scottsdale, Arizona.

10. Eversole, George (1990). "Rapid CNG Refueling: A Utility's View," presented at The Drive For Clean Air Natural Gas Vehicles Conference, Washington, D.C. September 17-19.

11. Filin, Nicolai V. (1989). "Complex of Cryogenic Equipment for Gas Supply of Residential Areas," presented at the Ninth International Conference on Liquefied Natural Gas, Nice, France, October 17-20.

12. Gram, Anker (1991). "Technical Breakthrough: What is Needed to Make LNG a Major Player in Vehicle Fuel Markets," presented at the Continental Conference on Natural Gas, Norman, Oklahoma.

13. Hovland, Siv. Ing. Odd (1991). "Liquefied Methane: The Transportation Fuel of the Future That Has Just Begun," presented at the European Conference on New Fuels and Clean Air, Antwerp, Belgium, June 19. 
14. Interagency Commission on Alternative Motor Fuels (1990). First Interim Report, September 30 .

15. International Energy Agency (1990). Substitute Fuels for Road Transport: A Technology Assessment, Organization for Economic Cooperation and Development, Paris, France.

16. Joyce, Thomas J. (1990). "Technical Advances, New Uses for LNG," presented at the LNG: Building Markets for the '90s Conference, Washington, D.C., November 1-2.

17. King, S.R. (1990). Presentation at The Drive for Clean Air Natural Gas Vehicles Conference, Washington, D.C. September 17-19.

18. Moulin, Pierre (1990). "NGV's: Three Main Options," presented at the International Congress Exhibition on the Use of Methane in the Transport Sector, Bologna, Italy, March 9-11.

19. Olifirov, F.N., V.M. Kalnin and A.I. Gulienko (1989). "Fuel Supply and Control Systems for Commercial Aircraft Engines Using Liquefied Natural Gas," presented at the Ninth International Conference on Liquefied Natural Gas, Nice, France, October 17-20.

19a. Patrick, Jim (1991). The 90s: Decade of Environmental Concern/Action," presented at Natural Gas Vehicles: Today \& in the Future Conference, Austin, Texas, March.

20. Pehrson, Nancy C. (1991). "LNG Vehicle Demonstration Projects," presented at Society of Automotive Engineers meeting, Portland, Oregon, August.

21. Ritchey, Benjamin, W. Sheppard, M. Murphy, D. Russell, J. Francis, A. Turanski, J. Hoess and R. Schmelz (1990). Effects of Alternative Fuels on the U.S. Trucking Industry, report prepared for the ATA Foundation, Inc., Trucking Research Institute, Alexandria, Virginia, November 9.

22.

(1991). "Effects of Alternative Fuels on the U.S. Trucking Industry," presented at the New Fuels for Cleaner Air Conference, Phoenix, Arizona.

23. Stephènson, John (ed.) (1990). Natural Gas Vehicles 1990, International Association for Natural Gas Vehicles position paper.

24. Stephenson, John (1991). Leaming From Experiences With Compressed Natural Gas as a Vehicle Fuel, Centre for the Analysis and Dissemination of Demonstrated Energy Technologies, Analyses Series No. 5, Sittard, The Netherlands.

25. Topaloglu, Toros (1990). "Ontario's Natural Gas Bus Program," presented at the Eighth Annual Natural Gas Vehicle Conference, Washington, D.C., September 17-19.

26. Vernon, Bruce (1991). Fax communication and telephone conversation, September 17. 


\begin{tabular}{|c|c|c|c|c|}
\hline $\begin{array}{l}\text { Document Control } \\
\text { Page }\end{array}$ & $\begin{array}{l}\text { 1. SERI Roport No. } \\
\text { TP-230-4638 }\end{array}$ & $\begin{array}{l}\text { 2. NTIS Accession No. } \\
\text { DE92001204 }\end{array}$ & 3. & Recipient's Accession No. \\
\hline \multirow{2}{*}{\multicolumn{3}{|c|}{$\begin{array}{l}\text { 4. Title and Subtitle } \\
\text { Comparison of CNG and LNG Technologies for Transportation } \\
\text { Applications: Final Subcontract Report, June } 1991 \text { - December } 1991\end{array}$}} & \multicolumn{2}{|c|}{$\begin{array}{l}\text { 5. Publication Date } \\
\text { January } 1992\end{array}$} \\
\hline & & & \multicolumn{2}{|c|}{6.} \\
\hline $\begin{array}{l}\text { 7. Author(s) } \\
\text { J.E. Sinor }\end{array}$ & & & 8. & $\begin{array}{l}\text { Performing Organization Rept. } \\
\text { No. }\end{array}$ \\
\hline \multirow{2}{*}{\multicolumn{3}{|c|}{$\begin{array}{l}\text { 9. Performing Organization Name and Address } \\
\text { J.E. Sinor Consultants, Inc. } \\
7960 \text { Niwot Road, Suite } 12 \\
\text { P.O. Box } 649 \\
\text { Niwot, CO } 80544\end{array}$}} & 10. & $\begin{array}{l}\text { ProjectTask/Work Unit No. } \\
\text { FU121010 }\end{array}$ \\
\hline & & & 11. & $\begin{array}{l}\text { Contract (C) or Grant (G) No. } \\
\text { (C) CJ-1-11145-1 } \\
\text { (G) }\end{array}$ \\
\hline \multirow{2}{*}{\multicolumn{3}{|c|}{$\begin{array}{l}\text { 12. Sponsoring Organization Neme and Addreas } \\
\text { National Renewable Energy Laboratory } \\
1617 \text { Cole Blvd. } \\
\text { Golden, CO } 80401\end{array}$}} & 13. & $\begin{array}{l}\text { Type of Report \& Poriod } \\
\text { Covered } \\
\text { Technical report, June } 1991 \text { - } \\
\text { December } 1991\end{array}$ \\
\hline & & & \multicolumn{2}{|l|}{14.} \\
\hline
\end{tabular}

15. Supplementary Notes

16. Abstract (Lmit: 200 words)

This report provides a head-to-head comparison of compressed natural gas (CNG) and liquefied natural gas (LNG) supplied to heavy-duty vehicles. The comparison includes an assessment of the overall efficiency of the fuel delivery system, the cost of the fuel supply system, the efficiency of use in heavy-duty vehicles, and the environmental impact of each technology. The report concludes that there are applications in which CNG will have the advantage, and applications in which LNG will be preferred.

17. Document Analysia

a. Descriptors alternative fuels, compressed natural gas, liquefied natural gas, heavy-duty vehicles, fuel transportation systems

b. Identifiors/Open-Ended Torms

C. UC Categories 421

18. Availability Statement

National Technical Information Service

U.S. Department of Commerce

5285 Port Royal Road

Springfield, VA 22161
19. No. of Pages

52

20. Price

A04 

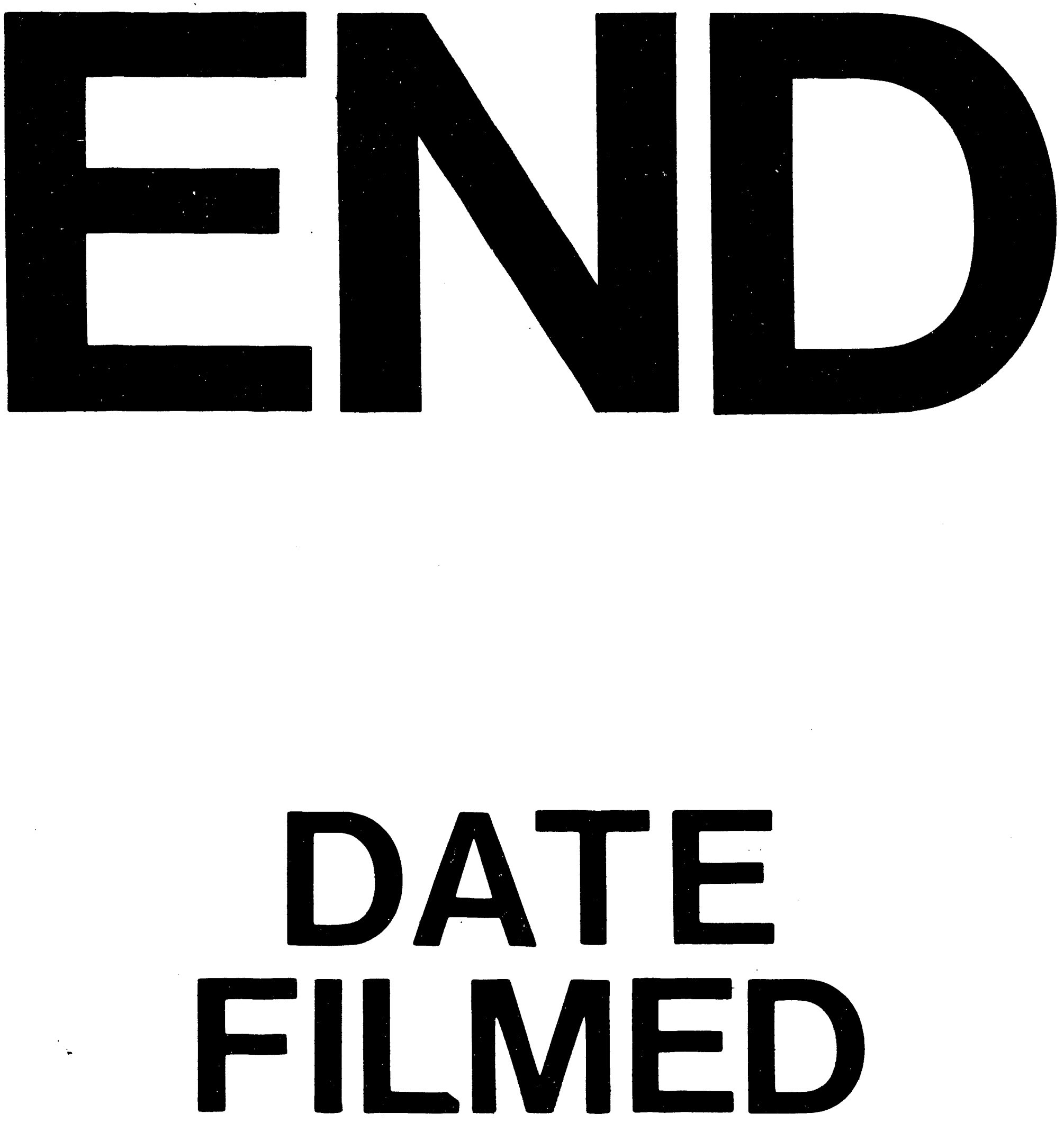

1

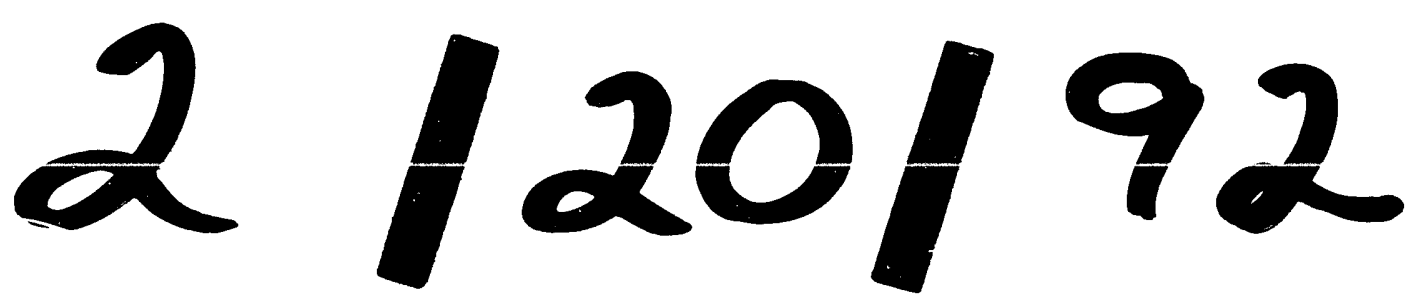


